\title{
DESARROLLO Y COMPLEJIZACIÓN DE LAS SOCIEDADES tardías de la Costa Central: El caso de Ychsma
}

Francisco Vallejo Berrios*

\begin{abstract}
Resumen
El presente trabajo intentará esbozar un cuadro general para el periodo Intermedio Tardío en la costa central en base a las nuevas evidencias arqueológicas y estudios desarrollados. Intentar establecer precisamente cuales son los factores de cambio en las sociedades tardías de la costa central y específicamente de la sociedad ychsma será uno de los elementos que abordaremos en este estudio tomando como base de discusión los conceptos de cultura y espacio; estilo y talleres cerámicos. Finalmente trataremos de establecer una correspondencia entre los cambios climáticos y la evolución del periodo Intermedio Tardío tomando en cuenta que los cuadros existentes de oscilación climática parecen coincidir en muchos aspectos con los puntos de cambio más importantes que se dan en las sociedades tardías. Sin necesidad de caer en un determinismo climático, es evidente que también estos factores influyeron fuertemente en el desarrollo de las sociedades costeras de los andes peruanos en diferentes periodos.
\end{abstract}

Palabras clave

Ychsma, complejización, costa central peruana, cultura y espacio, periodo Intermedio Tardío, estilo cerámico, cambios climáticos.

\begin{abstract}
This research study presents a general review of the Peruvian Central Coast during the Intermediate Late Period based on new archaeological evidence and current studies. We intend to establish the factors of change in the Ychsma society. To do this, we discuss the concepts of culture, space, style and ceramic workshops. Finally, a preliminary identification takes into account tables of climatic oscillation and association with the evolution of societies during the Intermediate Late Period and are used as evidence to interpret these complex change.
\end{abstract}

\section{Keyword}

Ychsma, complexity, peruvian central coast, culture and space, Late Intermediate period, ceramic style, climatic oscillation.

\footnotetext{
* Universidad Nacional Federico Villarreal. Correo electrónico: f_vallejob@yahoo.com
} 


\section{INTRODUCCIÓN}

Aunque el periodo Intermedio Tardío (PIT) en la costa central ha sido ampliamente tratado en diversos trabajos, es claro que aun estamos lejos de una comprensión cabal del mismo en términos de precisar por ejemplo sus inicios y cuando es el momento de ruptura con el Horizonte Medio. De hecho, este problema ha sido abordado puramente desde el punto de vista de estilos cerámicos y aun en este caso falta mucha precisión y concordancias al respecto. No es el único problema por supuesto que presenta serias interrogantes, la caracterización misma del periodo Intermedio Tardío entorno al desenvolvimiento temporal del mismo y como las sociedades involucradas se desarrollan en términos económicos y sociales resulta hasta el momento un misterio.

Si bien la secuencia cerámica ychsma que hemos presentado anteriormente para la sociedad ychsma (Vallejo, 2004) puede servir de herramienta para el ordenamiento del material arqueológico y especialmente para la correspondencia cronológica de muchos contextos, las implicancias directas de la misma solo pueden entenderse en base a la asociación y explicación de estos contextos con sus respectivas épocas y fases. La cerámica como tal, no solo representa una manera de entender a una sociedad a través de su iconografía o producción, sino que constituye además una herramienta fundamental de ordenamiento cronológico para muchos contextos arqueológicos que aparecen mayormente confusos.

En otras palabras, el resultado de una secuencia cerámica para la sociedad ychsma no debe entenderse, por lo tanto, como un simple ordenamiento de material cerámico sino que esta corresponde a determinas épocas y fases originadas en cada uno de los periodos de importantes cambios que la propia sociedad ychsma ha experimentado. La posibilidad de entender mejor a una sociedad a partir de sus cambios cronológicos reside precisamente en el hecho de definir cuales son los indicadores arqueológicos existentes que se manifiestan en estas líneas de cambio o de ruptura con la fase o época precedente. Definitivamente, estos momentos de cambio pueden obedecer a factores internos como externos, social o políticamente hablando, como también pueden llegar a tener correspondencia con factores medio ambientales que se suceden independientes de la dinámica propia de una sociedad. La división hecha a partir de rangos temporales de Temprano, Medio y Tardío, además de las respectivas fases existentes al interior de cada una de estas épocas, corresponden por ello, con procesos de cambio que la sociedad ychsma tiene y que sirven como base para una explicación mayor de esta sociedad.

Caracterización Del Período INTERMEdio TARDíO (PIT)

La definición de este periodo cronológico ha tenido un largo proceso de desarrollo, solo comparable con el mismo proceso de definición cronológica de la arqueología peruana (Ramón, 2005), donde los varios intentos de sintetización del proceso histórico-arqueológico andino conllevó a una estructuración de la cronología peruana en diversas etapas o secuencia general de amplia distribución tempo-espacial. El resultado de este largo y complicado proceso de síntesis derivó hacia dos propuestas marco, como la que aplica simplemente un criterio de cronología relativa (Rowe, 1959, 1962) y la que aplica un criterio evolucionista de tendencia explicativa procesual (Lumbreras, 1969). Ambas propuestas, desde el punto de vista estrictamente cronológico, son muy comparables y casi completamente correspondientes.

Por lo general, el PIT se ubica en la bibliografía especializada en promedio entre el 1,000 d.C. y el 1450 d.C., pero esta cronología puede variar según cada investigador ${ }^{1}$. De acuerdo con Bonavia (1991), en este periodo, el control 
político parece fundamental en el desarrollo de las culturas regionales y locales.

Definir el sistema o los sistemas políticos imperantes en este periodo resulta hasta el momento una tarea difícil. Algunos investigadores prefieren hablar de estados, reinos, confederaciones, señoríos o curacazgos, pero es claro que cualquier categoría aplicada aun resulta insuficiente para explicar el cuadro político y organizativo de las sociedades tardías, precisamente por su poco respaldo categorial antropológico e histórico en cada una de ellas. Por ello, a pesar de estos variados intentos de categorizar políticamente a las sociedades andinas durante el PIT, no siempre las categorías utilizadas representan elementos conceptuales que pueden ser comparables entre los distintos investigadores. Por ejemplo, la variedad de términos y categorías usadas para la definición genérica del PIT nos lleva a tener y usar distintas denominaciones o terminologías para el mismo periodo como las de: "Confederaciones tribales" (Tello, 1929); "Constructores de ciudades" (Bushnell, 1962); "Reinos y confederaciones" (Matos, 1966); "Estados regionales" (Lumbreras, 1969); "Formaciones Señoriales" (Paredes, 1988); o "Renacimiento de las culturas locales y regionales" (Bonavia, 1991).

Estas mismas terminologías, que de alguna manera intentan caracterizar al PIT, suelen utilizarlas indistintamente los investigadores que analizan los procesos o las culturas existentes en este periodo, según sea el caso o el territorio en estudio. Estas categorías de "señorío" o "curacazgo", han sido también de uso muy frecuente entre los etnohistoriadores que suelen investigar y calificar a las sociedades andinas tardías en base a las fuentes documentales (Rostworowski, 1972, 1978); categorías que siguen diversos investigadores (Agurto, 1984), aunque no siempre con el mismo significado.

Es a partir de estas categorías político-antropológicas provenientes de la etnohistoria, que los arqueólogos califican a varios de los grupos sociales existentes en el PIT. Así, por ejemplo, Morales (1984: 83) habla para este periodo en los Andes, como de "...una gran multitud de reinos y señoríos independientes...".

En cuanto a las características económicas del PIT, existen diferentes interpretaciones para este periodo, algunos ven una suerte de resurgimiento cultural y de un activo inter-cambio de productos a nivel interregional y a grandes distancias (Bonavia, 1991). Otros autores sostienen igualmente que, para la sierra central, este periodo se manifestaría también como de una fuerte integración socioeconómica, con alta densidad demográfica y numerosos asentamientos con arquitectura diferenciada (Parsons et. al., 2000). Al respecto Shady (1984: 13) señalaba que "Si bien, se puede reconocer áreas de desarrollo regional, la sociedades no vivieron en es-

1 Las libertades con las cuales se ha usado la periodificación absoluta de este periodo para la región Ychsma son numerosas confundiendo por ello la asignación temporal de muchos contextos. Las diferencias de asignación temporal para el PIT pueden ir de algunas decenas de años incluso a varias centurias como, por ejemplo: 1,2001,470 d.C. (Bueno, 1982); 1,200-1,440 dC. (Agurto, 1984); 900-1,470 d.C. (Eeckhout, 1999b, 2003); 1,220-1,440 d.C. (Negro \& Fuentes, 1989); 1,100-1,400 d.C. (Paredes, 1988); 1,000 a 1,100-1,460 d. C. (Shimada et. al., 2004); 1,000-1,450 d.C. (Silva \& Jaime, 2005); 900-1,470 dC. (Espejo, 2006). En otros casos, para la asignación cronológica se ha preferido el uso de unidades temporales más amplias como el de los siglos, así por ejemplo: siglo X- siglo XV (Eeckhout, 2003); siglo XI - siglo XV (Franco, 2004); siglo (Villacorta, 2004).

Para la cronologización absoluta del PIT (o de sus correspondientes temporales) existen varias propuestas generales para el área andina u otras áreas, como por ejemplo: 900-1,440 dC. (Bonavia, 1991); 1,100-1,450 dC. (Iriarte, 2004); 1,200 - 1,470 d.C. (Lumbreras, 1969); 1,000-1,400 dC. (Morales, 1984); 900-1,460 dC. (Shady, 1984); 1,000 - 1,470 dC. (Parsons et. al, 2004); 900 a 1,000-1460 dC. (Perales, 2005). 


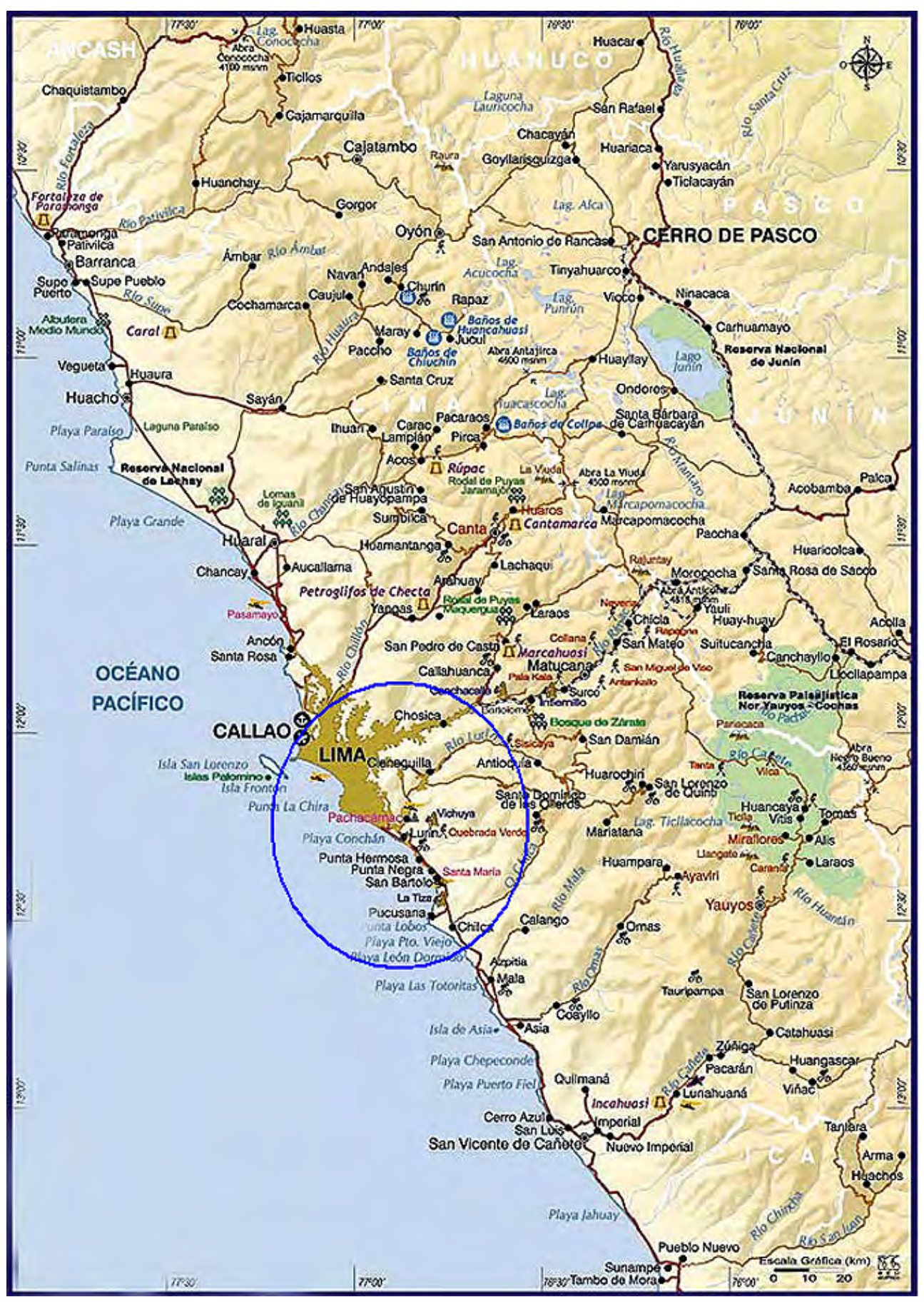

Figura 1. Mapa del área central andina con la región ychsma resaltada en círculo. 
tancos aislados; lo hicieron en permanente contacto y comunicación...".

Con todo, la percepción general de muchos investigadores en torno a las características sociales propias del PIT suele también variar de acuerdo al espacio y la unidad cultural analizada. Así, por ejemplo, en la sierra central, sierra sur e incluso el Altiplano, para algunos, este periodo está marcado, en lo social, por diferentes conflictos inter-étnicos que conducen a un aislamiento de los centros poblados en lugares altos e inaccesibles y a la construcción de murallas en torno a estos poblados. La aparente fortificación de muchos de estos poblados induce a varios investigadores a hablar, en efecto, de un periodo de extrema beligerancia (Nielsen, 2002). Los gobiernos fragmentados, los pequeños señoríos o la desorganización parecen ser también parte de las características de este periodo en la sierra central (Parsons \& Hastings, 1988; Perales, 2004) y sierra centro-sur (Lumbreras, 1969b).

Varias hipótesis se han esbozado al respecto, donde se ha buscado consecuentemente explicar este periodo de desorden o fraccionamiento en base a la desestructuración previa de las sociedades Huari y Tiahuanaco respectivamente. Parson et. al. (2004: 89) hablan por ello de un periodo de "descentralización organizacional", luego del colapso de los estados del HM en los Andes centrales seguido de un proceso caracterizado por nuevas formas de integración regional y local. Aunque en este tipo de hipótesis, ambos procesos, los del HM y los del PIT, se tratan de yuxtaponer mecánicamente partiendo de una suerte de orden y fuerte control político existente en el HM, sucedido por un periodo de caos y ruptura de los cánones sociales y políticos, establecidos precisamente por las sociedades Huari, lo cierto es que el colapso de Huari como entidad estatal fue anterior a este proceso de cambio.

La explicación mayormente aceptada es que cuando las sociedades Huari y Tiahuanaco decaen o desaparecen surgiría un proceso mayormente caótico y de guerra en la sierra, coetáneo con sociedades costeñas centralizadas y fácilmente distinguibles como Lambayeque, Chimú, Chancay o Chincha, por citar algunas de las más conocidas en la costa. De esta manera, ambos procesos paralelos conducirían al surgimiento de sociedades pequeñas de carácter autárquico y belicistas en la sierra y, en contraposición, sociedades muy dinámicas y complejas en la costa basadas en la concentración poblacional en grandes ciudades, altamente productivas y con un fuerte intercambio regional. Una suerte de dicotomía política y social entre ambas regiones que ya algunos investigadores han resaltado.

En los procesos de la costa, según Bonavia (1991), se pueden distinguir al menos dos grandes grupos, aquellos de la costa norte donde el impacto de la sociedad Huari fue relativamente escaso o corto y por ello un rápido resurgimiento de la culturas locales, y los de la costa sur donde se mantiene un periodo todavía conservador con los elementos culturales Huari producto de una larga tradición de contactos sierra costa. En cambio los procesos ocurridos en la parte central de la costa y áreas aledañas pudieran tener procesos particulares; Franco (2004), por ello, apunta hacia un proceso de reestructuración social en la costa en base al prestigio de varios centros religiosos, el cual dará pie para el establecimiento de importantes sociedades.

Con todo, varias interrogantes surgen a partir de estos planteamientos, la primera de ellas sería sí efectivamente el control político Huari, o alguno similar, se mantuvo hasta los finales del HM y, si a la desaparición de Huari, se suceden inmediatamente los procesos propios del PIT; por otro lado ison realmente diferenciados los procesos de la sierra con los de la costa durante los inicios del PIT?, y por último ilos procesos propios del surgimiento del PIT son procesos sincrónicos en toda la región andina?. 
La evidencia arqueológica, cuando es analizada en una escala andina en busca de una secuencia de síntesis, parece conducir a la sincronía y a ciertas generalizaciones regionales, pero cuando se trata de precisar la sucesión de eventos involucrados y los procesos locales, encuentra mucha dificultad. De hecho, existen varios elementos que no encajan en estos modelos explicativos como el de considerar, por ejemplo, que la ciudad de Huari, según todas las evidencias disponibles hasta el momento, se abandonó muy tempranamente en el HM hacia finales de la época 2B (Menzel, 1968). Si esto es válido, entonces aquellos indicadores basados en la existencia de fuertes estilos regionales de la época 3 y 4 del HM, muy notorios a nivel cerámico (Prumers, 2000) irepresentan acaso otras unidades políticas o culturales que bien pudieran considerarse como una suerte de estados regionales propios del HM?.

Si existe una sincronía entre el cambio del HM hacia el PIT en los Andes centrales, entonces habrá que considerar el hecho que los mismos factores de cambio afectaron a diversas sociedades al mismo tiempo en un espacio geográfico muy amplio y no se trata simplemente de la desestructuración de una sola sociedad hegemónica como Huari. En consecuencia nos preguntamos ¿Cuál sería el factor o los factores de cambio para el tránsito del HM al PIT en los Andes centrales ocurrido entre los 900 y los 1,000 dC.?

Las tesis de la singularidad histórica, presente en trabajos como el de Parsons et. al (2004) para la región Chinchaycocha-Tarama durante el PIT, basados en elementos particulares como la dualidad, los rituales o las guerras rituales por ejemplo y que intentan explicar a las sociedades andinas y sus procesos sociales como procesos únicos o sui generis en cada caso, impiden una explicación mayor de los cambios existentes al interior de cada sociedad a partir de un marco explicativo de orden general y procesual.
OsCILACIONES CLIMÁTICAS Y CAMBIOS EN EL INTERMEDIO TARDÍO

\section{Geomorfología de la costa central}

La costa peruana constituye comparativamente en los Andes, un espacio de terreno reducido, delimitado entre las elevaciones de los contrafuertes andinos por el Este, y el litoral marino paralelo hacia el Oeste bañado este con aguas del Océano Pacífico. Topográficamente la costa presenta cerros de poca altura, que generalmente forman sistemas de colinas alternados con pampas o terrazas, productos de los rellenos aluviales que han descendido desde la cordillera occidental; estos rellenos aluviales son de forma más o menos triangular, con el vértice introduciéndose hacia las estribaciones andinas y con la base en las orillas del mar. El relieve de estas terrazas aluviales es mayormente casi plano, con una pendiente suave en caída hacia el mar y se superponen directamente al sustrato geológico constituido por formaciones cretácicas.

Es importante señalar las características de estas terrazas aluviónicas, pues es sobre ellas donde posteriormente el hombre andino prácticamente ha desarrollado toda su actividad económica, ocupándolas intensamente. Estas terrazas se formaron durante la época pleistocénica del Cuaternario, probablemente durante los largos periodos de glaciación y como consecuencia de sucesivos deshielos de los glaciares alto-andinos, generándose gigantescos movimientos de masas aluviónicas que progresivamente descienden hacia la costa, sedimentándose y rellenando sus conos deyectivos con el material transportado.

En el caso del valle bajo del Rímac, por ejemplo, este es ocupado paulatinamente por los enormes depósitos aluviales pleistocénicos que descienden por la cuenca del Rímac, formándose finalmente un gran abanico aluvial de superficie uniforme, enmarcado entre los contrafuertes del Morro Solar por el sur y los afloramientos rocosos de San Jerónimo por el norte, 
llegando casi a unirse en este lugar con el cono deyectivo del Chillón. El material aluvial de relleno lo conforma por ello una mezcla de cantos rodados principalmente, con bancos de arcilla y arena; aumentando la densidad de los cantos rodados al centro del depósito y disminuyendo hacia sus extremos donde existe mayormente material arcilloso. En algunos puntos se nota la existencia de antiguos lechos fluviales, pero de dimensiones pequeñas y de distribución ramificada y errática, donde se acumulan delgados sedimentos de arena y limo. Este hecho, denota el carácter oscilatorio del cauce primigenio del Rímac, creando numerosos puntos de desborde que además contribuyeron al acrecentamiento del lecho aluvial en todo el cono deyectivo.

Estas terrazas aluviales son a su vez, regadas por ríos extrazonales que nacen en las cumbres de la cordillera occidental, sujetos a un régimen níveo-glaciar y pluvial. Son ríos en su mayoría de corto recorrido, discurren por lechos de pendiente pronunciada, muy fuerte en muchos casos y con numerosas rupturas de caída. Estos ríos son de tipo torrencial, con gran variación de su caudal a lo largo del año. En su descenso a la costa, forman verdaderos cañones interandinos, pues durante la estación de lluvias en la Sierra, los ríos erosionan profundamente las vertientes andinas y ya en la Costa, erosionan también en forma intensa su cauce, ocasionado desbordes e inundaciones temporales a los terrenos adyacentes.

Las áreas aledañas a los conos deyectivos principales, muestran un comportamiento algo diferenciado. En estas áreas priman los depósitos aluviales a manera de terrazas, constituidos por cantos semiangulosos con una matriz arenosa originados por lechos de ríos intermitentes, llamados Wad (Sébrier y Macharé, 1980), propios de las zonas desérticas. Estos lechos son a su vez cortados posteriormente por nuevas avenidas que degradan las terrazas preexistentes. Los conglomerados que se han formado a partir de estos wad, hacia comienzos del Cuaternario, están constituidos a partir del acarreo de material lodoso, areniscas, gravas angulosas y cantos redondeados o semiangulosos, cuando los fenómenos de lluvias locales en estas áreas desérticas eran significativamente mas frecuentes y de mayor envergadura. Los factores eólicos como la deflación, que afectó estos lechos aluviónicos pleistocénicos, han contribuido al empobrecimiento de estos suelos haciendo que en muchos casos primen los materiales líticos y arenas de grano grueso, en vez de los materiales arcillosos. Varias estratificaciones en estas áreas presentan costras salitrosas del tipo conocido como caliche que se forman por acción de la humedad atmosférica sobre los suelos salinos. En algunos casos, las superficies de estas áreas aledañas a los valles, son cubiertas también con arenas de grano fino provenientes del transporte eólico. En puntos donde la humedad se logra concentrar, a partir de la concurrencia de neblinas, se formarán microambientes muy particulares conocidos como lomas, las cuales parecen potenciarse principalmente en determinados periodos cuaternarios.

Adicionalmente, durante los períodos tardíos del Cuaternario, se comienzan a producir fuertes vientos desde el sur y suroeste que transportan y cubren con arena eólica extensas áreas, especialmente la parte baja y media de los valles. Es un proceso que en general afecta a toda la franja costera peruana, ingresando la arena inclusive varias decenas de kilómetros tierra adentro y desertificando amplias zonas de litoral.

\section{Climatología de la costa central}

Las características climáticas de toda la costa central peruana son muy similares. En este espacio geográfico, los datos indican una persistencia durante todo el Cuaternario de un clima hiper-árido y a su vez de gran humedad relativa, donde se pueden haber sucedido algu- 
nas fluctuaciones climáticas de corta duración. De hecho, todos los indicadores apuntan a una dependencia climatológica de la costa peruana a los factores oceanográficos, relacionados principalmente con la existencia de la Corriente Peruana fría (o corriente de Humboldt) y las cortas, pero significativas, alteraciones que se producen a partir del fenómeno de El Niño (Ortlieb y Macharé, 1989). La generalidad, sin embargo, es de una persistente aridez de la costa con ausencia notable de precipitaciones, salvo los casos esporádicos ya señalados y que se originan durante los fenómenos breves de $\mathrm{ENSO}^{2}$.

\section{Las oscilaciones climáticas globales del último} milenio

En el último milenio las oscilaciones climáticas han sido menores, las temperaturas se mantuvieron en general ligeramente inferiores a las actuales, aunque se han detectado oscilaciones significativas. Las causas de tales oscilaciones son muy variadas, aunque todas ellas pueden estar relacionadas con cambios externos al sistema climático, desde el aumento de la actividad volcánica, hasta la reducción de la actividad solar. Precisamente la relación existente entre los ciclos de actividad solar y las variaciones en los índices de temperatura global hace que esta sea la causa más probable de las grandes oscilaciones climáticas globales. Obsérvese al respecto la relación existente entre los gráficos representados en las figuras 2 (Bauer et. al, 2003) y 3 (Gonzáles Rouco et. al., 2003), donde las fluctuaciones climáticas son correspondientes con los ciclos de actividad solar.

Una de las primeras grandes fluctuaciones del último milenio corresponde a un periodo excepcionalmente cálido, denominado como Óptimo Climático Medieval (OCM) o Intervalo Cálido Medieval, ubicado cronológicamente entre el 1,000 y el 1300 dC, el cual afectó especialmente a todo el hemisferio norte. El máximo punto de temperatura alcanzado en este periodo cálido ocurrió alrededor de 1,100 a 1,150 dC. aproximadamente.

A mediados del XV se produce en contraposición con el OCM un enfriamiento global, conocido como la "Pequeña Edad del Hielo" (PEH) o "Little ice age" en inglés (Grove, 1988). No pareciera tratarse de un periodo continuo de índices de temperaturas medias por debajo de las actuales, sino que en su evolución se detectan distintas anomalías frías y cálidas de especial intensidad. La dinámica particular de este periodo y la variabilidad geográfica en la cual se manifiesta no son conocidas del todo,

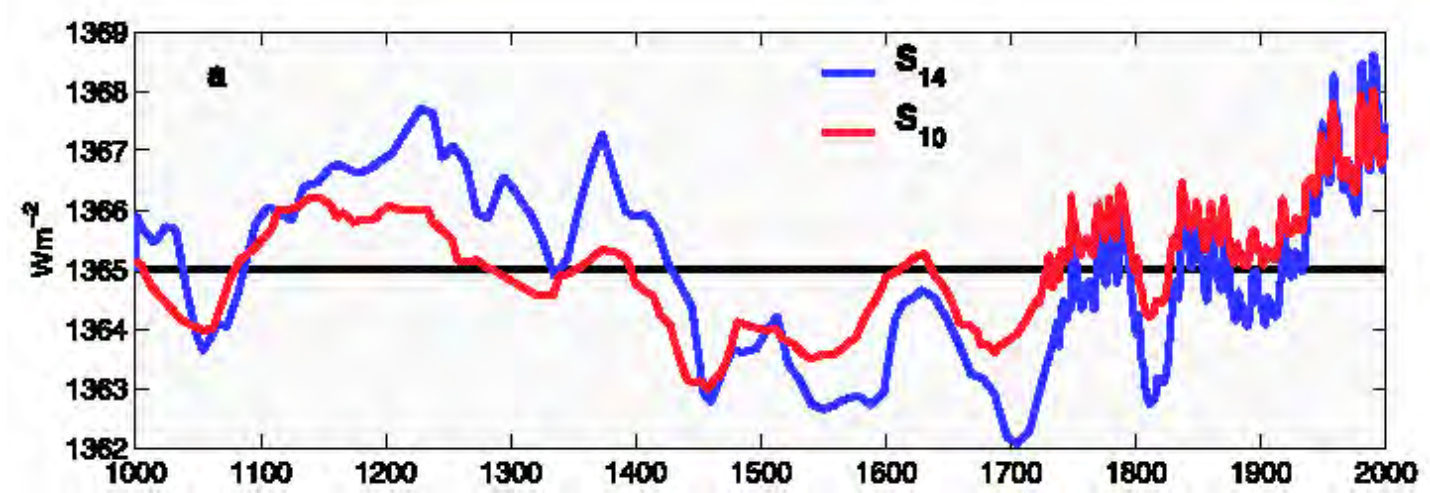

Figura 2. Variaciones en el ciclo solar del último milenio (Tomado de Bauer et. al., 2003).

2 El Niño Southern Oscillation. 


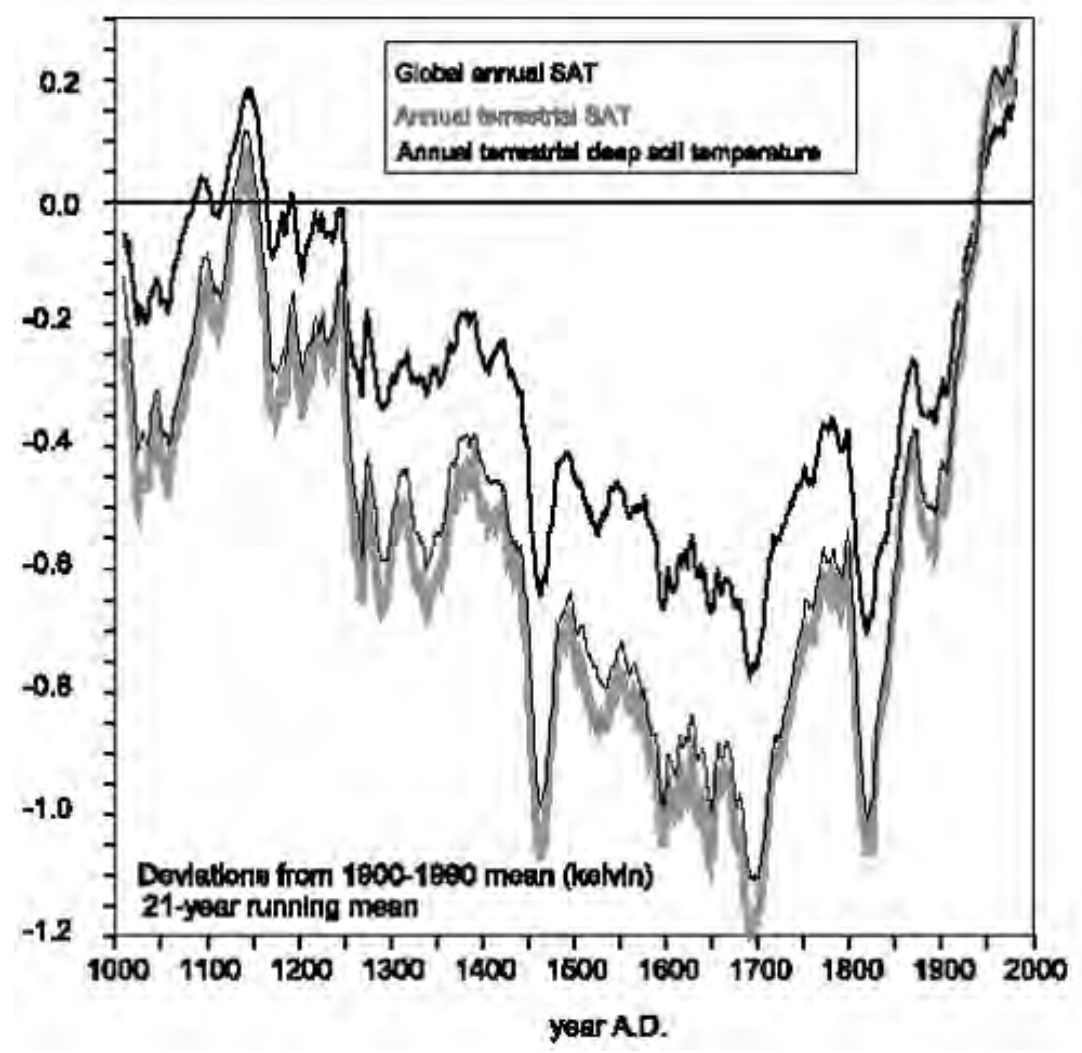

Figura 3. Variación en los índices de temperatura media global de los últimos mil años (tomado de Gonzáles Rouco et. al., 2003).

especialmente porque se trató de un fenómeno de alcances globales con diferentes comportamientos locales. Estas diferencias, en cuanto al comportamiento espacial de las anomalías climáticas, se pudieron deber a las diferentes características del medio geográfico y a los diversos mecanismos atmosféricos existentes sobre unos territorios u otros.

Las consecuencias de estas oscilaciones climáticas son aun poco claras en el hemisferio sur y especialmente en la región andina. Sin embargo, estudios recientes hechos por diversos investigadores (Ortlieb et. al, 2000) en la Bahía Mejillones al norte de Chile, demuestran la ocurrencia de estas oscilaciones climáticas para esta zona como las correspondientes con el OCM y la PEH. Otro caso es el registrado en el neva- do Quelccaya de Perú (Thompson et. al. 1994), donde se han hallado evidencias de importantes fluctuaciones en el grosor de la capa de hielo y evidencias de un fuerte fenómeno de lluvias de gran intensidad datadas para el año de 1500 dC. Estos fenómenos pueden ser también, de hecho, manifestaciones asociadas respectivamente con el OCM y la PEH. Con todo, cada vez son más las investigaciones referentes a clarificar las manifestaciones locales de estas oscilaciones climáticas globales en Sudamérica y en los Andes. Son en efecto varias las investigaciones que evidencian estos procesos con diferentes grados de afectación en el medio ambiente (Soon \& Baliunas, 2003; Thompson et. al. 1994; Villalba, 1994).

El episodio de Spörer, también conocido como el mínimo de Spörer, representa uno de 


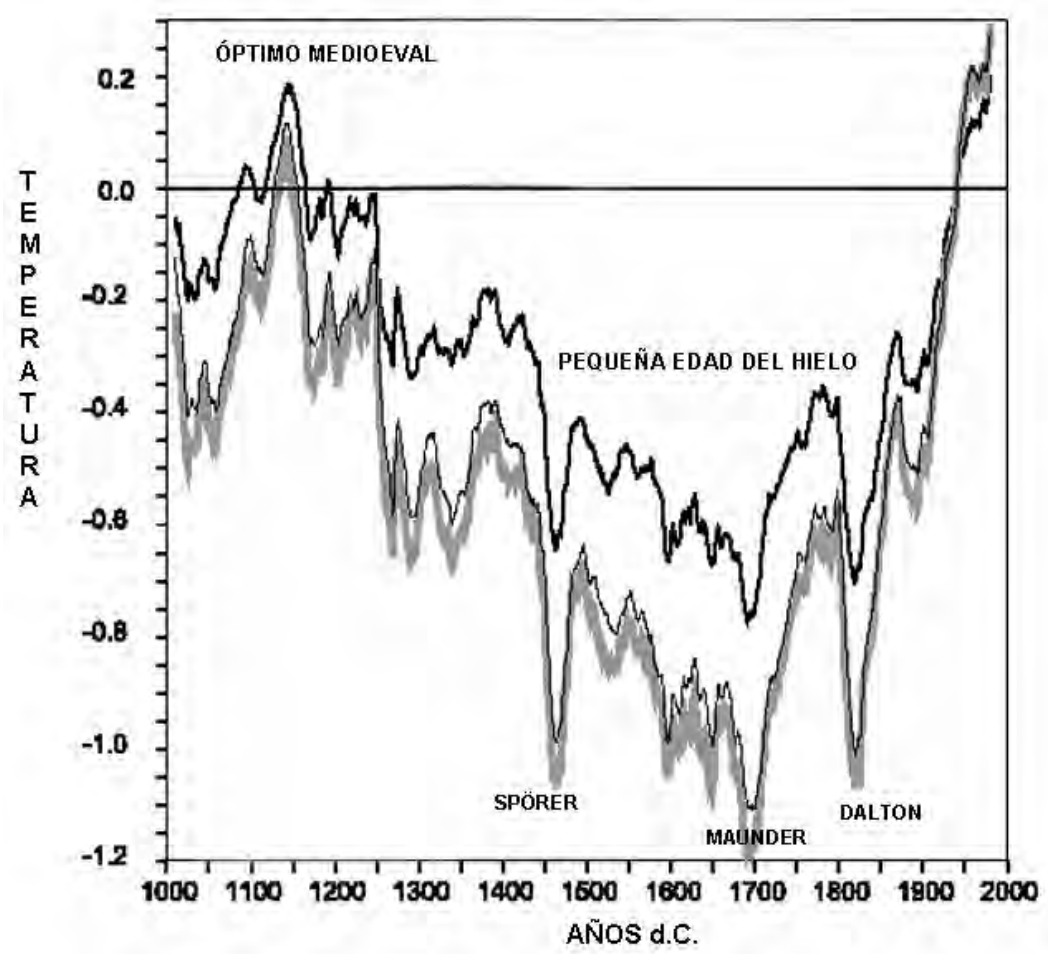

Figura 4. Oscilación climática del último milenio con presencia de los eventos del OCM y de la PEH (Basado en Gonzáles-Rouco et. al., 2003). Notése los picos en el diagrama conformados por el Optimo Climático Medioeval y el evento de Spörer que prácticamente encuadran el Periodo Intermedio Tardío.

los picos de menor temperatura ocurrido en épocas tempranas de la PEH, el cual es datado aproximadamente hacia mediados del siglo XV. Sin embargo este episodio se dio inicio hacia la primera mitad del siglo XV, agudizándose su efecto alrededor de 1460 - 1470, y concluyendo hacia finales del mismo siglo.

Las oscilaciones climáticas globales y los Andes centrales

De acuerdo con Dollfus \& Lavallee (1973) en los momentos que se presentaron las crecidas de los glaciales en las altas cumbres andinas el desierto costeño era cálido y soleado, pero expuesto a algunas lluvias ocasionales debido a la disminución del dinamismo del anticiclón del Pacífico Sur.

La geografía y clima de la Sierra corresponde mayormente con una topografía muy escabrosa, suelos marginales a excepción de los fondos de los valles con suelos fértiles, promedios de temperaturas bajas con heladas frecuentes, una distribución de lluvias muy irregular e incluso sequías que pueden durar varios años. La Cordillera de los Andes tiene una influencia muy significativa en las variaciones de la temperatura del aire, dando por ello lugar a una variedad de climas.

Las actividades económicas agropecuarias de subsistencia en la Sierra están sujetas a muchas variables como la geografía, el piso altitudinal, el tipo de suelo, las condiciones climáticas y la topografía de los valles. Un descenso en las condiciones térmicas e hídricas pueden fácilmente conllevar a la pérdida de cultivos como por ejemplo el maíz y la papa en su fase de floración secándolos por la exposición a bajas temperaturas. La helada, la sequía y el granizo 
son los elementos meteorológicos más riesgosos para las actividades agropecuarias. Las heladas en la Sierra y en el Altiplano se producen en altitudes superiores a los 3,000 m.s.n.m., aunque en algunas zonas dependiendo de la topografía del terreno pueden presentarse incluso bajo esta altitud. Se presenta por lo general, en las noches de cielos claros y son provocadas por un balance de radiación negativo, ligado a la ausencia de nubes y a una humedad atmosférica débil. Los daños que ellas provocan sobre los cultivos pueden ser catastróficos, a nivel del suelo la temperatura puede descender hasta $10^{\circ} \mathrm{C}$ bajo cero lo que prácticamente destruye los cultivos agrícolas.

La sensibilidad del área de cultivos superiores a los 3,000 m.s.n.m. en la Sierra a las condiciones climáticas muy marcada, siendo por lo tanto importante cualquier variación significativa en los valores promedio de temperaturas mínimas que soportan estas áreas ${ }^{3}$. Lhomme y Vacher (2003) en base a estudios específicos sobre el uso de los camellones en el Altiplano, demuestran que esta técnica hace subir la temperatura asociada al nivel de los cultivos en los camellones en alrededor de $2 \mathrm{C}^{\circ}$ con los cuales es posible contrarrestar los efectos de las heladas nocturnas. Es claro entonces que un descenso de apenas pocos grados en las temperaturas promedio para estas áreas haría inválido este recurso tecnológico para las frecuentes fluctuaciones en las temperaturas mínimas que vienen relacionadas con los periodos secos.

Por otro lado, las sequías son períodos secos prolongados y corresponden con ciclos climáticos. Se caracterizan en la Sierra por la falta de precipitaciones pluviales. El origen de estas anomalías climáticas se encuentra en la atmósfera, en donde los niveles de humedad decrecen. La Sierra sur (Puno, Cuzco, Apurímac; Arequipa, Moquegua y Tacna) es la más propensa a estos fenómenos recurrentes, siendo las actividades agropecuarias superiores a los 3,500 m.s.n.m. las más susceptibles de enfrentar un desastre económico por efectos de la sequía. En estas altitudes las actividades agrícolas son menores teniendo preponderancia las actividades de pastoreo.

Lhomme y Vacher (2003) encuentran que los camellones del Altiplano muestran evidencias de diferentes épocas de uso y abandono, quizás relacionados con cambios climáticos o políticos. Una de estas épocas de abandono la asociarían con el decaimiento de Tiahuanaco alrededor del año 1,000 d.C. Por otra parte, en sus investigaciones en Machu Picchu, Wright et. al. (1999), encuentran importantes datos asociados con la ocupación del sitio y las variaciones climáticas, según los autores citados, un clima más seco y de menor precipitación parecen coincidir con los primeros 50 años de ocupación del sitio. En otras palabras, el ambiente de selva alta, que actualmente es visible en Machu Picchu, pudo haber tenido una configuración diferente hacia mediados del siglo $\mathrm{XV}$, lo cual debió seguramente favorecer el establecimiento del sitio.

Para la costa es necesario efectuar mayores investigaciones a fin de determinar el grado de afectación de estos cambios climáticos. De hecho un descenso en las temperaturas medias influenciaría en modificaciones en los patrones climáticos locales que normalmente se presentan en esta región. El descenso de la temperatura puede estar asociado por ejemplo, a un aumento en la humedad relativa que por

3 En condiciones especiales, las heladas pueden afectar en muy poco tiempo enormes áreas. A manera de ilustración y ejemplo, apenas hace pocos meses, en Febrero del 2007, se produjo uno de estas heladas meteorológicas que obligó a declarar en emergencia los departamentos de Huanuco, Cerro de Pasco, Junín y Huancavelica. Algunas zonas del Cuzco también fueron afectadas. Las fuentes del Ministerio de Agricultura estimaron que fueron 67,999 has de cultivo afectadas y alrededor de 26,977 has las que se perdieron totalmente. 
lo general se expresa en una mayor recurrencia de neblinas. Muchos "eventos húmedos" en la costa detectados en varias investigaciones arqueológicas, pudieran estar asociados a la aparición de lomas y de una garúa constante, que a eventos esporádicos ENSO que se caracterizan por su corta duración y especialmente por sus efectos erosivos sobre el terreno.

Por citar un caso que actualmente venimos investigando, en los recientes trabajos arqueológicos desarrollados en Huacho, en el sitio de Cerro Colorado - sector Los Pinos (Díaz, 2007), se ha logrado definir grandes cambios climáticos asociados con determinados contextos arqueológicos. Por citar un caso, el grado de afectación por humedad detectado en muchos de los contextos arqueológicos hallados, evidencia notorios eventos húmedos que en este caso no están restringidos a los clásicos eventos ENSO, sino más bien a largos periodos de gran humedad que permitieron la aparición de lomas en las laderas arenosas y comúnmente desérticas de Cerro Colorado. Los contextos asociados con estos eventos húmedos evidencian la aparición de raíces y un grado de descomposición orgánica que definitivamente no corresponden a ocasionales lluvias sino a un lapso temporal mucho mayor que permitió la aparición de vegetación arbustiva en estos secos arenales y grados de humedad en el terreno capaces de descomponer casi todo el material orgánico asociado en estos contextos arqueológicos. Esto demuestra que la costa peruana también habría estado sujeta a estas fluctuaciones u oscilaciones climáticas de gran magnitud, alternándose consecuentemente pequeños periodos húmedos con largos periodos de extrema sequedad.

\section{Cambios climáticos e influencia en las socieda- des del Intermedio Tardio}

El medio andino es particularmente sensible a los cambios climáticos que se dan a nivel global. Específicamente la costa peruana, depende mucho de sistemas hidrológicos de carácter glacial establecidos en las alturas de los Andes. De hecho, fluctuaciones en los niveles niveo-glaciares de los Andes peruanos tienen incidencia directa en los ecosistemas naturales y sistemas de agricultura de la costa, estos últimos muy dependientes del volumen en agua de los ríos, de su estabilidad de carga y especialmente de permanencia de un periodo de carga de los ríos capaz de sustentar los periodos agrícolas.

La incidencia de factores climáticos de orden mundial, capaces de alterar los niveles de temperatura y volumen de la corriente fría de Humboldt y que incidirán en la ocurrencia de fenómenos contrapuestos por la corriente cálida del Niño, son elementos que deben ser estudiados con mayor precisión. Sin necesidad de caer en un determinismo climático, es evidente que estos factores influyeron fuertemente en el desarrollo de las sociedades costeras de los andes peruanos en diferentes periodos.

Auque pueda hasta el momento haberse enfocado mal este aspecto, no se puede soslayar que los eventos del tipo Niño pudieron incidir en la caída o surgimiento de sociedades en la costa peruana. Si bien es cierto, que las sociedades costeras estuvieron ya acostumbradas a estos eventos, y aun siendo capaces de soportar un fenómeno del Niño particularmente agresivo, una sucesión de estos eventos en un tiempo relativamente corto pudieron haber hecho que estas sociedades tuvieran poco tiempo para reconstruir sus espacios agrícolas y especialmente sus sistemas de riego, marcando el colapso de sistemas políticos o de estructuras sociales vigentes.

Cuando analizamos la evolución del periodo Intermedio Tardío (PIT) no nos podemos sustraer al hecho de que muchos de los eventos más importantes que caracterizan precisamente este periodo tengan de alguna manera coincidencia con las principales fluctuaciones climáticas que se dieron a nivel global. El hecho mismo 
que el inicio del PIT se encuentre cronológicamente ubicado aproximadamente entre los 950 dC y los 1,050 d.C. guarda estrecha correlación con el inicio de un proceso de calentamiento terrestre conocido como el Optimo Climático Medieval. Es decir, un cambio fundamental en la cronología de los Andes el tránsito del Horizonte Medio al PIT, se encuentra al parecer enmarcado dentro de un proceso de cambio climático de características globales. Este importante tránsito cronológico y cultural afectó a gran parte de los Andes centrales y es particularmente visible en los cambios producidos en los patrones culturales de varias sociedades costeras.

Los cambios en los patrones culturales se dan muchas veces de manera drástica durante este periodo, al punto que aquellos elementos, antes comunes en varias sociedades costeras a nivel de diseño y de representación iconográfica, desaparecen para dar paso a elementos muy locales propios de cada sociedad que surgirá independientemente en este periodo. Sociedades fuertemente identificadas con patrones culturales propios como Lambayeque, Chimú, Chancay o Chincha tienen, en reglas generales, comportamientos de cambio muy comparables unos a otros. La situación es particularmente homogénea en la costa central y en el norte chico, donde se comparten muchos elementos comunes, tanto a nivel cultural como geográfico.

Si bien los periodos finales del HM son en esencia casi desconocidos, algunos elementos nos llevan a pensar en una suerte de confluencia común entre las sociedades costeras de este periodo en la región señalada, donde aun se comparten muchos patrones culturales establecidos seguramente en la época 2 del HM, notoriamente el periodo de mayor influencia cultural Huari y en el que es posible hablar, con una fuerte evidencia material de respaldo, de una unidad política común en los Andes centrales que algunos investigadores definen como una sociedad hegemónica o imperial llamada Huari (Menzel, 1968; Lumbreras, 1980). Pero a diferencia de la época 2 y algo de la 3, los indicadores existentes hasta el momento para la época 4 señalan mayormente que no existiría ninguna unidad de tipo político entre todas estas sociedades costeras a diferencia de las épocas anteriores del HM y que, más bien, estas sociedades se encuentran ya avanzadas en un proceso de independencia cultural de carácter regional y local, que en muchos casos puede incluso reducirse solo al tamaño de un solo valle.

Cabe ahora preguntarnos si en la época 4, aun considerando esta suerte fragmentación política y territorial de los antiguos centros Huari de las épocas 2 y 3 en la Costa y, también considerando que en la época 4 se comparten todavía muchos elementos culturales comunes entre estas sociedades costeras ipor qué la tendencia es hacia una "archipieligización" cultural y política del espacio territorial costero? y ipor qué, ya en los inicios del PIT, las diferencias culturales entre cada una de esta "unidades señoriales tardías" resultantes, son tan marcadas?.

Ciertamente pueden ser muchas las posibilidades que existen para explicar este fenómeno, pero también es cierto que este mismo fenómeno afecta a prácticamente todos los Andes centrales y es, por lo tanto, un fenómeno que debe ser explicado no como tendencias solo regionales o locales, sino que este debe ser entendido como parte de un proceso mucho más general. Por ello, ya asumiendo que la probable unidad política y cultural Huari de la época 2 ya había desaparecido hacía mucho tiempo en el escenario de los Andes centrales para época 4 ipor qué existió todavía un proceso posterior tan generalizado y horizontal, cronológicamente hablando, que rompe con todos los cánones culturales anteriores y da inicio al PIT?; en todo caso icuál sería el denominador común para todos estos cambios simultáneos en un espacio geográfico tan grande y tan diverso? 
Cuando analizamos de manera más amplia el panorama cronológico establecido para los Andes centrales, vemos inmediatamente que estos ciclos periódicos que alternan sucesivamente procesos de homogenización cultural con procesos de independización o regionalización cultural parecen constituir una regla común de cambio social, económico o cultural para todo este espacio y en donde nuevamente se podría pensar en un denominador común para todos ellos. El hecho mismo de pensar en un denominar común para todos estos procesos tiene siempre el riesgo de caer en un tipo de determinismo que haya condicionado la evolución y el desarrollo cultural de las sociedades andinas. El carácter contrapuesto y notoriamente inverso de cada uno de estos procesos, tanto de los llamados procesos horizontales o comunes como de los llamados procesos regionales o independientes, también definiría en esencia el carácter mismo del territorio andino.

Una explicación que busque este denominador común podría, por estas razones, enfocarse en el factor geográfico. En resultado, deterministamente hablando, la tendencia de los Andes centrales, con geografía y territorios tan diversos, conduciría necesariamente hacia la fragmentación política del espacio y "archipieligización” cultural de las sociedades y, donde, a su vez, los factores geográficos que aíslan una región de otra o un valle de otro potenciarían aun más las diferenciaciones culturales. Así, a falta de una unidad política fuerte y hegemónica que centralice el control del territorio en los Andes centrales, la tendencia natural sería siempre hacia la fragmentación política del territorio y a la particularización cultural de las diversas sociedades existentes.

Otra explicación adicional o quizás complementaria, recalcaría el papel que juega el factor étnico, donde precisamente la identificación y pertenencia por grandes grupos po- blacionales hacia determinado grupo étnico, se superpondría a cualquier tendencia de homogenización cultural que era inherente en cada uno de los tres horizontes culturales que la cronología andina acepta. En otras palabras, la estructura étnica resultaría más importante y de mayor trascendencia que cualquier suerte de imposición o condicionamiento cultural que se ejercería durante estos llamados horizontes; por ello, la estructura étnica resurgiría siempre, luego que los factores que originan y mantienen la "horizontalidad" cultural entran en decadencia.

La búsqueda de denominadores comunes para la explicación de procesos históricos en sociedades desaparecidas no es nueva, en realidad va a la par de la propia construcción de las principales teorías históricas. En un inicio, las principales explicaciones que se tenían para entender la desaparición de tal o cual sociedad estaban basadas principalmente en los factores ocasionados por la guerra y los movimientos de conquista territorial de un pueblo sobre otro. Los trabajos de Schliemann en Troya y los relatos históricos de conquistas hicieron pensar en el factor determinante de la guerra para la desaparición de las sociedades. Las ciudades abandonadas eran pues el reflejo de estos factores.

Con el tiempo, junto con el desarrollo de las teorías antropológicas, se puso énfasis en los factores migratorios y la sustitución de unas poblaciones por otras. La idea de pueblos dinámicos en busca de nuevos territorios era la explicación más común para entender también el por qué existían sustituciones de una cultura por otra. La arqueología, a través de sus métodos estratigráficos parecía dar sustento científico a estos esquemas y en donde se podía ver claramente in situ la superposición de una tradición cultural por otra. Como es fácil de comprender, la manipulación de este tipo de explicaciones históricas llevó rápidamente 
a la creencia de pueblos superiores en marchas épicas a través de territorios extensos.

Algunas décadas después, con el desarrollo de las teorías sociales, algunas de ellas muy influenciadas por el materialismo histórico, surgieron explicaciones que se basaban principalmente en los factores de cambio social y económico que toda sociedad tiene. Los procesos propios e innatos a toda sociedad eran, en ese sentido, los determinantes para entender la evolución de una sociedad a través del tiempo. Las corrientes difusionistas, muy enraizadas en el caso de las explicaciones anteriores, perdieron peso ante las explicaciones procesuales de orden social y evolutivo. El uso de categorías como la Formación Económico Social (FES), el modo de producción y especialmente, el papel determinante dado a las contradicciones que surgen al interior de la estructura de una FES, es el modelo interpretativo usado para explicar donde se producirían los cambios cualitativos en una sociedad dada.

En la actualidad, el desarrollo de las teorías ecológicas, los factores antrópicos sobre el medio ambiente y precisamente, el entendimiento de la dinámica propia del medio ambiente a través de los cambios climáticos, es el tipo de explicación, digamos de moda, que es más frecuente ver en los distintos trabajos de investigación. Según este tipo de planteamientos, los cambios más importantes en el desarrollo cultural y social, que son verificables a partir de la metodología arqueológica, encuentran explicaciones casi siempre relacionables con los factores climáticos, especialmente en el caso de cambio drástico en el patrón cultural dado en un territorio determinado. Este tipo de explicaciones son usuales hallarlas en los grandes tránsitos de una etapa o de un periodo a otro, aunque en el caso del Perú se ha puesto mucho énfasis en los fenómenos de tipo ENSO. Aunque las posibilidades de determinar cambios sociales y culturales completos a partir del fenómeno del Niño o de los llamados Meganiños, parecen ilimitadas en la explicación histórico-arqueológica dado que evidencias de este fenómeno o desorden climático son frecuentes de hallar asociadas a diversos contextos o estratos arqueológicos.

Pero entonces iexisten denominadores comunes para explicar los cambios importantes en las sociedades o la aparente desaparición de estas? O se trata más bien de una mezcla de diversos factores y en donde, según sea el caso, determinado denominador común resulta el primero o el más importante en una cadena de eventos temporalmente sucesivos los cuales conllevaran a un cambio radical en el comportamiento cultural y político de una sociedad.

Explorando la variable climática y su incidencia en los procesos culturales, notamos que esta pareciera si haber tenido una clara influencia en varios de los procesos de cambio generalizado que se dan en los Andes. De hecho, ya varios investigadores han resaltado este aspecto o dejado abierta la posibilidad de que los cambios climáticos hayan tenido, en efecto, una incidencia relevante sobre los procesos que llevan a cambios fundamentales en los Andes. Solo para el caso del surgimiento de Huari como entidad estatal fuertemente centralizada y su consiguiente expansión hacia otras regiones limítrofes hay varias propuestas que toman el condicionante climático como uno de los elementos principales, sino el principal, para este proceso (Isbell, 1986; Paulsen, 1983).

De igual manera para el tránsito entre el HM y el PIT, diversos investigadores utilizan la variable de los cambios climáticos en un sentido determinante (Agurto, 1984) o la indican señalando que estos solo hayan servido de marco a procesos sociales y culturales que dieron origen precisamente a este tránsito cultural (Bonavia, 1991). De acuerdo con Agurto (1984) "Se supone que los cambios climáticos, que se sucedieron entre los siglos XI y XII, afectaron gravemente la agricultura de secano que se practicaba en la sierra 
y el altiplano, así como a su ganadería, determinando una seria depresión económica y difíciles condiciones de vida".

Los factores de presión social y económica sobre algunos pueblos de la sierra a partir de los cambios climáticos y el descenso de las temperaturas pareciera haberse presentado gravemente a mediados del siglo XV. Regiones más sensibles a estas fluctuaciones climáticas, a los descensos continuos y marcados de temperatura, y a las múltiples consecuencias locales que debieron haberse generado a partir de estas anomalías parecen haber llevado a casos específicos donde se tuvo que optar por un replanteamiento completo de las estrategias usuales de subsistencia. En suma es el factor económico el que está actuando de manera determinante, pero en donde este mismo factor económico se ve afectado y condicionado por los cambios climáticos de envergadura.

La idea de una expansión incaica surgida desde principios del siglo XV motivada por estos detonantes económicos no resulta tan peregrina tomado en consideración que otros investigadores han señalado procesos similares para otras épocas y otros grupos étnicos. Ya hemos visto que en el caso de Huari, sus procesos de expansión hacia otros espacios ecológicos, existen intentos de relacionarlos directamente con la variable climática (Isbell, 1986; Paulsen, 1983). Para el caso incaico, el enfriamiento del medio ocurrido desde finales del siglo XIV y comienzos del siglo XV, pueden haber empujado gradualmente a la sociedad incaica a una crisis productiva en sus pisos ecológicos más altos, llevando progresivamente a un fortalecimiento de los estamentos militares en perspectiva de la apropiación violenta de otros espacios productivos foráneos. El propio proceso de expansión incaica, o mejor dicho, la incorporación del elemento de dominio étnico y el copamiento militar de otros espacios físicos por la sociedad incaica del PIT durante el siglo XV, pueden ser el resultado de una estrategia de compensación económica o la búsqueda de nuevas alternativas económicas ante un empobrecimiento o deterioro del medio debido a cambios climáticos adversos para la reproducción de un sistema adecuado a anteriores condiciones productivas.

Ciertamente, debe existir una explicación causal para el mutamiento de una sociedad habitualmente confinada a su propio territorio a una sociedad de carácter expansivo. Históricamente se pueden encontrar diversos detonantes específicos a este proceso, pero es claro que se trata de un proceso mucho más complejo donde se requiere una sumatoria de hechos que hace que determinada sociedad, como la incaica del PIT, pase a un nuevo tipo de organización social, mucho más jerarquizada, militarizada y con una economía dependiente de los nuevos territorios anexados.

En el caso concreto del PIT, Shady señalando a los grupos Chanca y Yauyos por ejemplo, indicaba que: "Los pueblos altoandinos, de regiones frías, con limitados cultivos de altura y pastoreo disperso, se enfrentaron a condiciones geográficas desfavorables. En ciertos casos, unas veces en forma individual y otras organizados en confederaciones de pueblos...invadieron y conquistaron, anexando territorios de otros grupos..." (1984: 13-14).

\section{Cultura y espacio}

El concepto de cultura siempre ha sido de difícil comprensión por parte de las diversas corrientes antropológicas. Ya anteriormente Kroeber y Kluckhohn (1952) intentaron sistematizar las diversas significaciones que existían hasta ese entonces sobre el término cultura, no llegando a un consenso. El debate aun continua hoy a la par que la antropología ve disminuir cada vez más su objeto de estudio. En cierta manera, pareciera que todos sabemos que la "cultura" está ahí, que tiene su propia existencia y dinámica, pero no podemos describirla ni decomponerla en sus partes integrantes. El concepto de cul- 
tura pasó con el tiempo de una definición muy selectiva del comportamiento social a una definición absoluta total del mismo.

El verdadero papel de la cultura en el desarrollo social y especialmente en los procesos de innovación o difusión que toda sociedad experimenta suelen ser puntos controversiales. Si bien en la base económica de toda sociedad actúan preponderantemente los elementos de orden económico ligados a la estructura misma de la sociedad, es cierto que la cultura como tal mantiene una actividad en cierta medida independiente de los factores económicos y puede ser que condicione en muchos casos a estos. Esto le otorgaría un papel determinante a la cultura en el comportamiento social, sin embargo, en el proceso del desarrollo social es aun difícil definir cual es el factor de cambio más importante. Una posición más intermedia, de compleja interacción entre varios factores, explicaría como todos ellos se dependen a si mismos de manera constante. Quizás los procesos de innovación y difusión también pueden conjugarse de una manera dialéctica, donde ambos factores interactúan de manera permanente. Esta discusión está implícita en las frecuentes interrogantes que nos hacemos permanentemente desde la arqueología al tratar de definir el por qué cambian las sociedades que son materia de estudio y cuales son los mecanismos específicos que intervienen en estos cambios.

Para los arqueólogos, el concepto de cultura está íntimamente ligado con la evidencia material que determinada sociedad ha dejado en un espacio y un tiempo limitado; en consecuencia el término de cultura implica muchas veces una correspondencia directa con el concepto de sociedad; por ello algunos prefieren hablar directamente de organización social o sociedad como el equivalente al de cultura. Definitivamente los elementos materiales solo son una parte de la sociedad y gracias al empleo adicional de conceptos como contexto, asociación y recurrencia por ejemplo es que podemos realizar interpretaciones mayores que nos acercan hacia el funcionamiento de la sociedad en su conjunto.

Si buscásemos una definición más acorde con aquello que, en nuestro concepto, constituye una cultura arqueológica, es la que señala que esta es un conjunto asociado de materiales que definen patrones contextuales establecidos por ello en un periodo de tiempo determinado y en una ubicación definida en el espacio. En otras palabras, la cultura arqueológica es la expresión física del comportamiento social. Cuando, a través de la metodología arqueológica, somos capaces de segregar o aislar este conjunto de patrones es que podemos hablar de una cultura. El manejo de categorías tempo- espaciales (Lumbreras, 1981), como la recurrencia y su manifestación corológica resultan fundamentales para definir la existencia y ubicación de una cultura.

Con todo, este concepto de cultura tiene sus limitaciones para la interpretación social pues únicamente se basa en los elementos materiales susceptibles de ser identificados. Como fácilmente podemos percibir, este tratamiento del concepto de cultura en la arqueología nos lleva a su vez al uso del término de cultura material. Así, el concepto de cultura arqueológica deviene por sus propios orígenes, en un criterio puramente clasificatorio y por lo tanto segregacionista o aislacionista. En la realidad históricosocial, este tipo de segregaciones de culturas es prácticamente imposible pues todas las sociedades humanas que comparten espacios próximos interactúan siempre de alguna manera entre si, además está el hecho de que muchas veces comparten antecedentes históricos y culturales comunes. Los aislamientos de materiales arqueológicos en base a su pertenencia "cultural" deben ser entendidos, en estrictu sensu, solo como parte de los procesos clasificatorios arqueológicos que deben llevar necesariamente a posteriores interpretaciones y mayor acercamiento hacia la 
realidad histórico-social. Quizás la diferencia mayor con los procesos tipológicos iniciales de materiales arqueológicos estriba en que la clasificación que usa el concepto de cultura identifica y se basa en comportamientos sociales recurrentes.

Siendo para la arqueología las evidencias materiales los indicadores principales de la existencia de tal o cual cultura, se ha tomado muchas veces los rasgos estilísticos como los elementos tipo para establecer una posible cultura. Bajo este aspecto, la cerámica ocupa quizás el primer lugar como indicador de una cultura arqueológica, debido a su gran posibilidad de conservación y por lo extensivo de uso. La arquitectura y las prácticas funerarias son igualmente grandes indicadores de la existencia de determinada cultura (también los instrumentos líticos en el caso de sociedades paleolíticas). Los textiles, la escultura, los metales y demás evidencias materiales son todas susceptibles de ser utilizadas en la identificación de una cultura arqueológica pero no siempre se han conservado o no han sido de uso muy extensivo.

De hecho, lo primordial en el trabajo arqueológico para la definición de una cultura es la identificación de patrones de expresión material así como de los patrones recurrentes de conducta. Sin embargo, estos mismos patrones de conducta se modifican gradualmente con el tiempo experimentando variaciones que también son susceptibles de ser identificadas por la arqueología a través de fases.

La cultura, ya esta en su sentido antropológico, influye en el comportamiento de los seres humanos al interior de la sociedad, cualquiera que esta sea; por ello, cuando hablamos de un cultura determinada, hablamos de comportamientos comunes y de sus expresiones materiales similares. Los elementos culturales están íntimamente interrelacionados entre ellos, por lo tanto, una innovación es una variación en un patrón cultural preexistente que es aceptada y transmitida hacia otros miembros de la sociedad.

\section{Variabilidad productiva, variabilidad cultural $o$ diferenciaciones étnicas}

$\mathrm{Si}$ analizamos detenidamente las manifestaciones de una cultura arqueológica en un área geográfica en particular, con diferentes ecosistemas a su interior, veremos que en general estas diferenciaciones del medio condicionaron variantes en el comportamiento y en las características de cada grupo humano asentado en ellas. Elementos como la arquitectura, los sistemas de riego y el patrón de asentamiento muestran claras evidencias de esta suerte de diferenciación basada en la adaptación al medio local. De hecho, la arquitectura representa uno de los mayores indicadores de esta variabilidad, no solo por sus condiciones de conservación hasta el presente, sino principalmente por su asociación directa con el medio. Observando la arquitectura presente en cada zona notamos diferencias marcadas en ella, especialmente en los tipos constructivos, que utilizan preferentemente el material disponible en cada zona. Aún, el tamaño, forma y altura de las edificaciones se encuentran fuertemente condicionados por estos localismos zonales. Resulta por ello difícil establecer diferenciaciones étnicas o culturales basándose en estas características de variabilidad, cuando es probable que solo sean simples adaptaciones al medio dentro de una misma estructura étnica.

De alguna manera, la cerámica puede presentar varias de estas tendencias hacia los localismos zonales, notándose ciertos tipos cerámicos que son mucho más recurrentes en determinadas zonas. Si bien, entre las características productivas de la cerámica, como el tipo de arcilla empleado y la pasta resultante obedecieron preferentemente al material disponible en cada zona, las formas o los elementos decora- 
tivos deben en cambio mostrar cierta uniformidad conceptual e iconográfica correspondiente con el criterio de unidad estilística. Sin embargo, en algunos casos la situación puede ser algo diferente, pues la presencia de algunos tipos cerámicos en determinadas zonas geográficas con marcadas diferencias iconográficas puede indicar la coexistencia al interior de una sociedad de diferentes subgrupos étnicos o culturales.

\section{El territorio Ychsma}

La necesidad de definir el territorio ychsma y sus áreas periféricas pasa necesariamente por la definición de los rasgos culturales ychsma, especialmente en su expresión material o en su sentido arqueológico. Aunque las fuentes etnohistóricas pueden enriquecer esta visión del espacio ychsma, es claro que se requiere una definición objetiva del territorio aplicando un metodología arqueológica.

También es necesario aclarar el aspecto interno de la región ychsma, en el supuesto de que convivan varios grupos étnicos y que estos se expresen en diferencias cerámicas o si estas diferencias correspondan a otras variables sociales o culturales.

Las descripciones coloniales para la región se refieren exclusivamente a la organización existente durante el periodo Inca, quedando apenas indicado o mencionado algunos elementos muy sueltos sobre la organización social anterior a los incas (Albornoz 1967; Santillán 1968 [1563]), correspondiente con el periodo arqueológico Intermedio Tardío y que venimos llamando también como periodo Ychsma. Dado que varios de los trabajos posteriores publicados por Rostworowski $(1972,1978)$ que utilizan documentos coloniales de archivo, apuntan a una suerte de unidad étnica y política entre los valles bajos de Lurín y del Rímac, parece muy probable que esta región sea efectivamente el área nuclear de la sociedad o cultura Ychsma (Cornejo 2000; Díaz y Vallejo 2003b). Otras áreas limítrofes al entorno de esta región base, como los valles medios, en especial la región llamada chaupiyunga y el valle bajo del Chilca, parecen corresponder al resultado de influencias culturales y religiosas de la sociedad Ychsma especialmente ocurridas durante el periodo incaico.

\section{Estilo y TALLERES CERÁMICOS}

Kroeber (1969) en un ensayo sobre el concepto de estilo apuntaba a entender a este bajo el dominio de la forma. Para Kroeber, la forma y específicamente la integración de las formas en modelos o grupos relacionados hace posible la identificación coherente de un estilo. Es lo que hoy entenderíamos como un conjunto de elementos de diseño y expresión basados y/o sujetos a un formato común, que en realidad serían formatos comunes cuando descomponemos las partes integrantes de un estilo. Tanto el concepto de estilo como el mucho mayor concepto de cultura, tienen dificultades para una definición técnica, lo cual hace que la arqueología no alcance todavía los rangos de precisión científica que se requiere para la interpretación de los múltiples elementos y contextos arqueológicos a partir de estos conceptos. Esta dificultad metodológica ha hecho que muchos investigadores abandonen la aplicación de las categorías de cultura o de estilo para el análisis de una sociedad, por estar ambas impregnadas de fuerte tendencia subjetivista en su definición.

En arqueología, el concepto de estilo, aplicado a la cerámica, debe tener presente de manera integrada los elementos tecnológicos, morfológicos y decorativos que implica cada pieza cerámica. Si bien en el intrincado proceso de definición de un estilo cerámico, se hace muchas veces prevalecer determinado elemento para el ordenamiento taxonómico, este debe ser entendido como un paso temporal en la definición de todo el corpus cerámico de un determinado estilo. Los procedimientos de clasificación estilística, por eso, en sus fases iniciales, no 


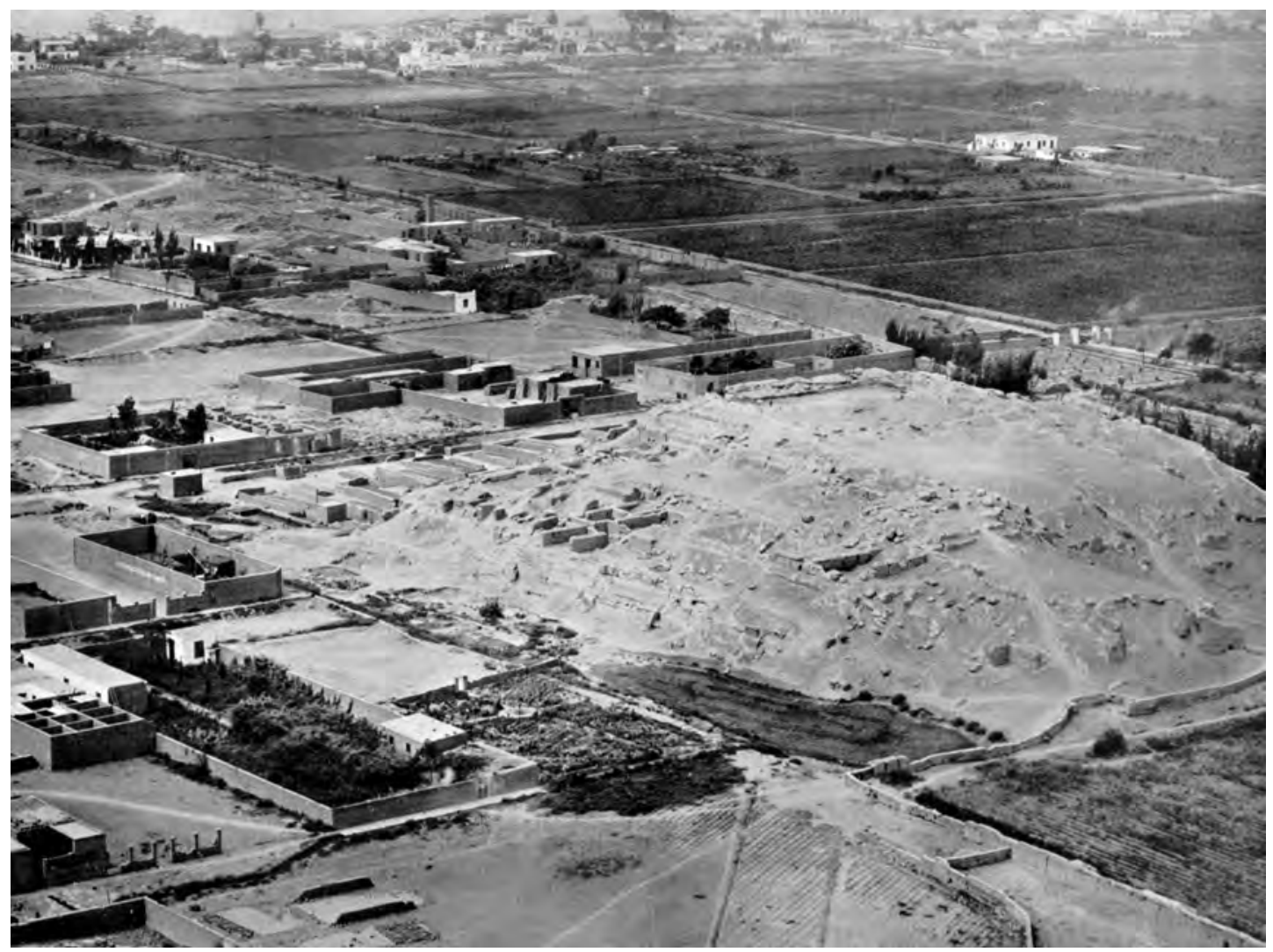

Figura 5. La Huaca San Miguel en una antigua fotografía aérea de finales de la década de 1920 (Johnson, 1930). La arquitectura ychsma medio, típica del valle bajo del Rímac, incluía importantes estructuras de gran volumen elaboradas con la técnica de tapiales y rellenos sucesivos divididos en varias fases constructivas, tal como se presentaba en los sitios de Armatambo, Mateo Salado, Santa Catalina, Macactampu, Huaca Tres Palos, entre otros. Todos estos sitios representaban durante el ychsma medio las sedes principales de los curacazgos existentes en aquella época.

deberían usar libremente el término de "estilo" para designar apenas a algunos rasgos tecnológicos o a determinados tipos cerámicos que solo son parte de todo un grupo mayor. El estilo es un todo, un conjunto, es la sumatoria de diversos rasgos formalizados y comunes tanto a nivel tecnológico como especialmente a nivel morfológico y decorativo.

Desde hace algunos años se han intensificando los estudios arqueológicos sobre la cerámica tardía en la costa central en el caso específico de Ychsma, tanto en su posición cronológica específica como en sus características formales (Bazán, 1990; Eeckhout \& Feltham, 2004; Guerrero, 2004; Makowski \& Vega-Cen- teno, 2004; Vallejo, 2004, 2005). Varios son en efecto los elementos involucrados, pero se ha puesto mayor énfasis en los aspectos secuenciales de la cerámica tardía, así como en su pertenencia estilística. Definitivamente, cuando enfocamos el estudio hacia el problema del estilo en la cerámica tardía, nos encontramos con rangos de variabilidad en la misma que hacen difícil establecer grupos homogéneos, estilísticamente hablando, que compartan de manera similar o equivalente, elementos productivos, morfológicos y de diseño.

Aun contándose con algunas informaciones etnohistóricas, y tomando muchas veces, como premisa la posición geográfica de los grupos ce- 


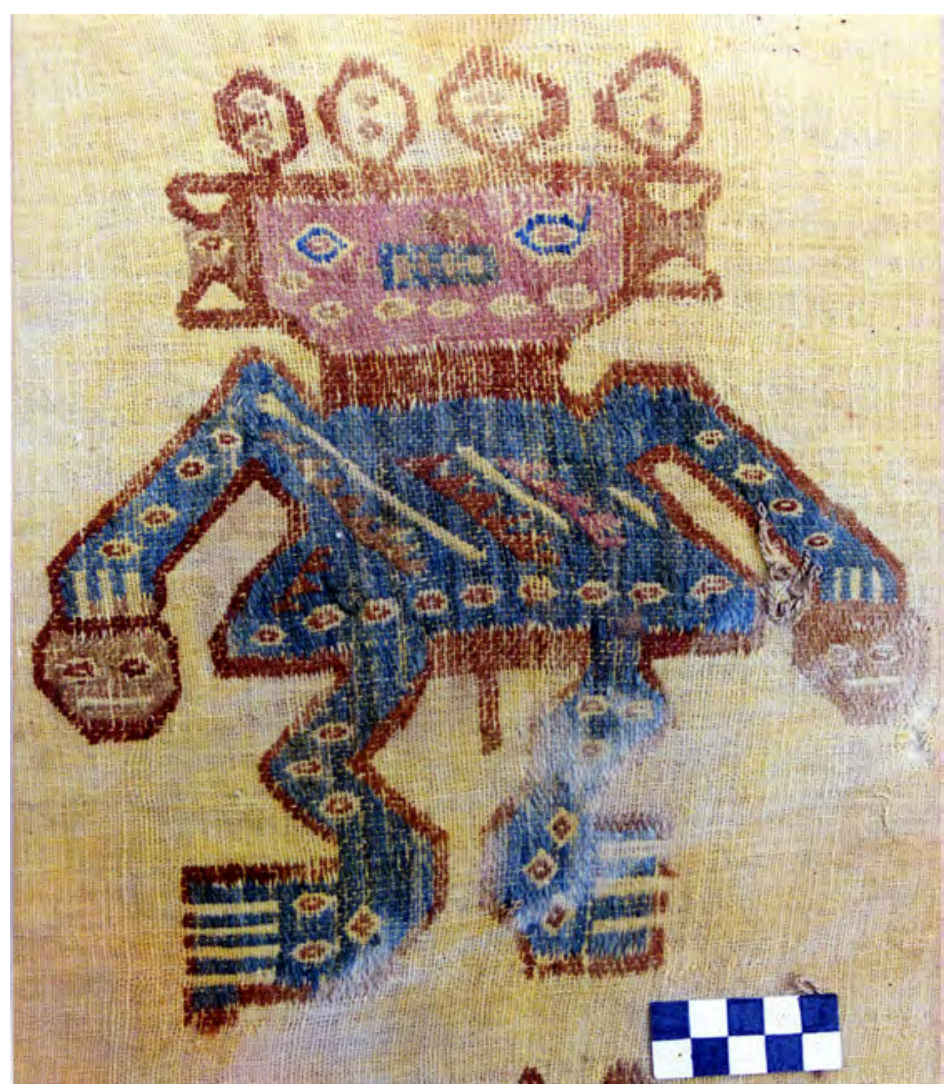

rámicos, estos resultan difíciles de clasificar por los ya señalados problemas de variabilidad que se dan al interior de un valle e incluso en áreas más restringidas del mismo valle. La variabilidad de la cerámica tardía en la costa central, es un elemento que debe ser asumido como inherente a la misma, aun cuando esta conforme grupos estilísticos mucho más amplios.

\section{Los cambios en la sociedad} Ychsma y la secuencia cerámica

Conceptualmente hablando, lo cambios en los patrones estilísticos no necesariamente
Figura 6. Textil ychsma tardio proveniente de Armatambo con la representación de un personaje semidesnudo que porta cabezas trofeo en ambas manos (Museo de Antropología y Arqueología UNMSM). Durante la época ychsma tardío comienzan a aparecer nuevas imágenes y representaciones de personajes y deidades que denotan un acrecentamiento de las estructuras de poder religioso y civil al interior de la sociedad ychsma.

fundamentales en la sociedad o solo expresar cambios graduales en un estilo, que por necesidad metodológica nos encontramos obligados a descomponer y clasificar en grupos independientes. La plasmación de una "secuencia" perfecta en ese sentido es muy difícil y muchas veces las secuencias cerámicas combinan ambos elementos de aproximación a la realidad.

Para el caso de la sociedad ychsma, el criterio de segregación o de subdivisión por periodos y fases intenta de hecho aplicar ambos conceptos. De esta manera, los periodos Temprano, Medio y Tardío en el estilo ychsma hemos tratado de hacerlos coincidir con periodos de grandes cambios en la sociedad ychsma. La subdivisión adicional en fases, sin excluir también su posible correspondencia con cambios importantes en la sociedad, se basa mayormente en cambios puntuales en los patrones estilísticos expresados exclusivamente en la cerámica.

Al definir y analizar las fases cerámicas ychsma, nota- 


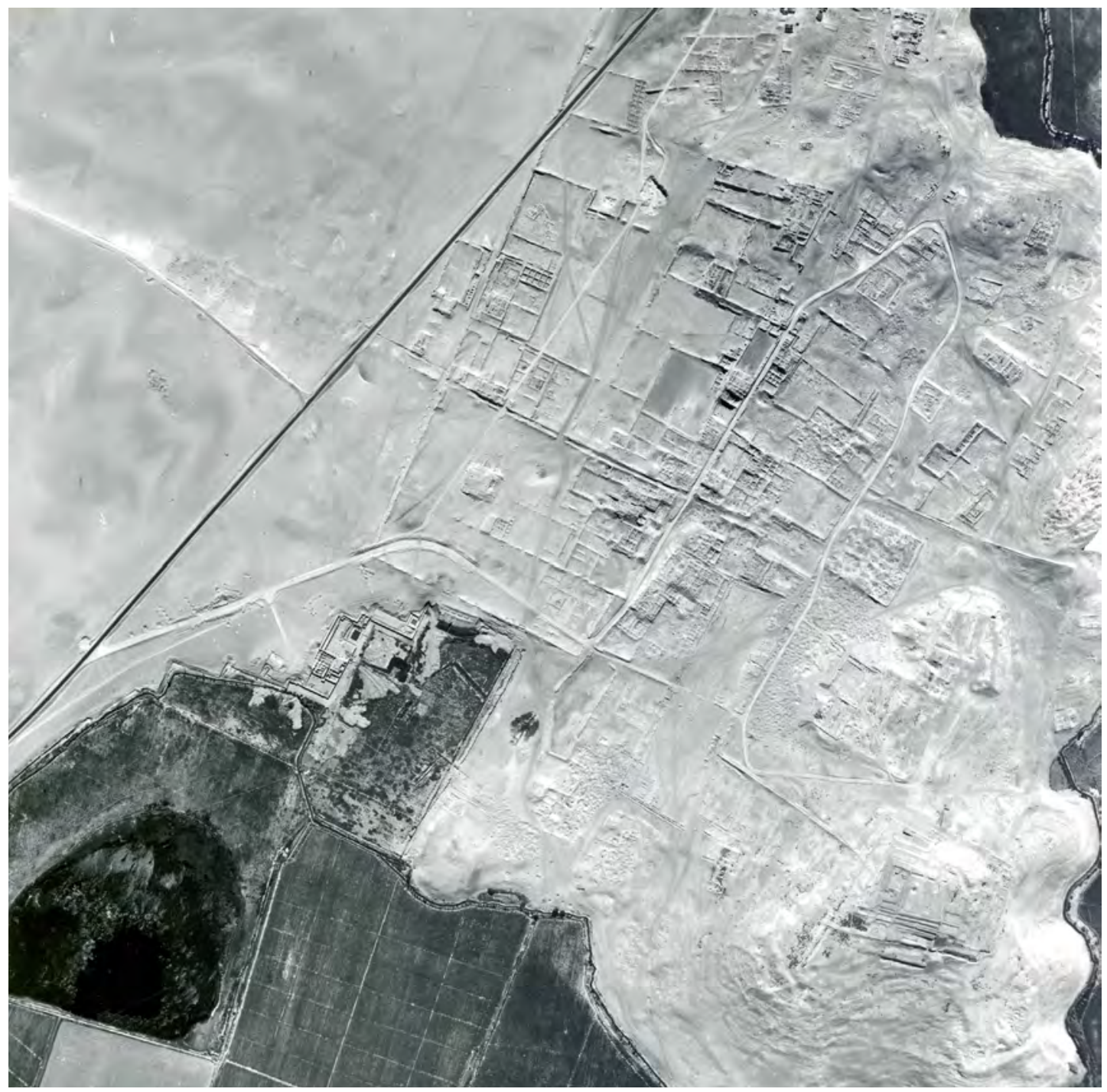

Figura 7. Foto aérea de la ciudad santuario de Pachacamac en el valle bajo de Lurín (SAN 1943). Pachacmac representa un caso extraordinario de continuidad ocupacional y constructiva en una misma urbe por varios periodos cronológicos. Sin embargo, su desarrollo más importante quizás fue durante la época ychsma tardío donde se construyen numerosos edificios conocidos como Pirámides con Rampa que se añaden a la antigua trama urbana del sitio. El prestigio alcanzado por Pachacmac durante este periodo fue uno de los principales motivos por el cual el estado incaico propició un culto panandino a Pachacamac y grandes peregrinajes hacia el lugar.

mos cambios importantes que de hecho deben involucrar a todo el conjunto de la sociedad. Por ejemplo, la pérdida de policromía en la cerámica, caracterizada en el periodo Ychsma Temprano visible en el cambio de la fase A a la $\mathrm{B}$, debe coincidir con cambios fundamen- tales en la situación social o económica, pues no solamente se abandona durante este periodo de cambio la policromía cerámica sino que adicionalmente muchas técnicas cerámicas son también olvidadas o entran en franco desuso. 


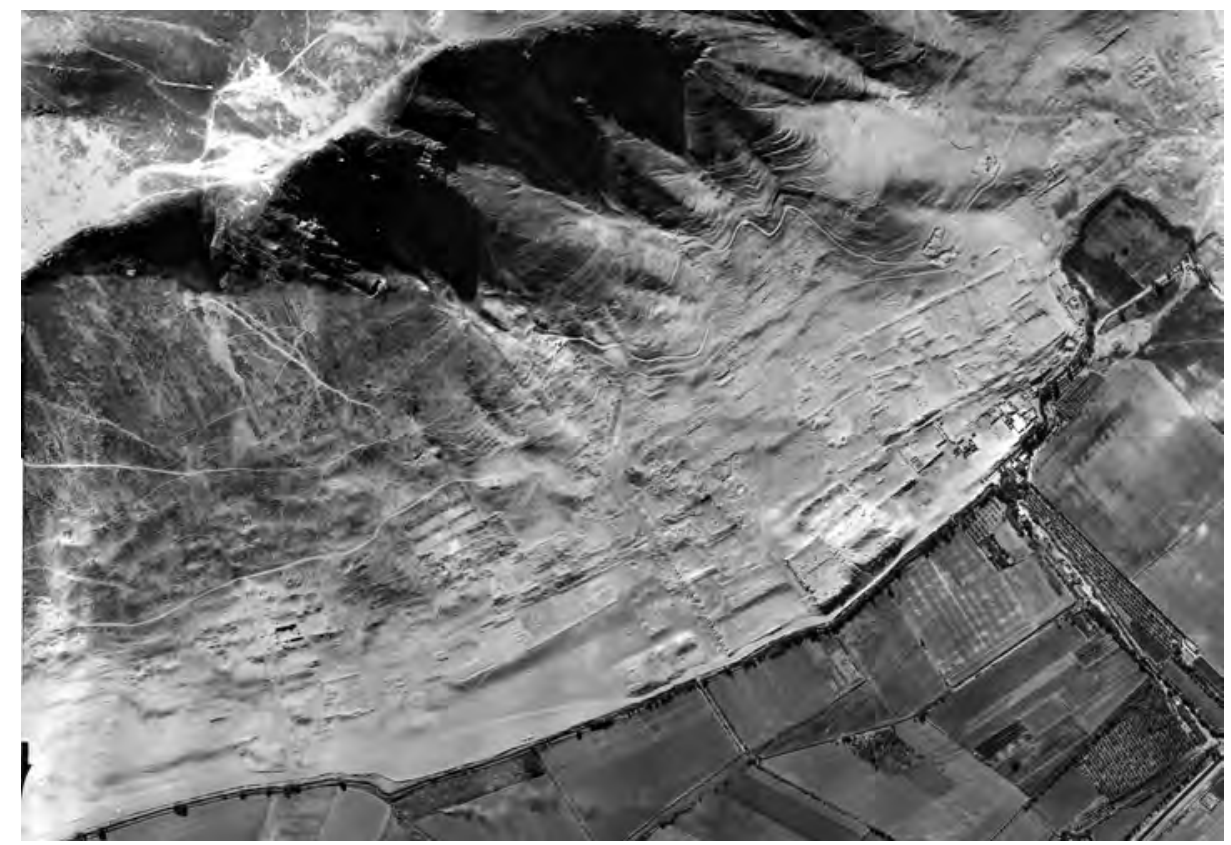

Figura 8. Foto aérea del sitio de Armatambo (SAN 1943). Armatambo fue la sede del curacazgo de Sulco, uno de los más importantes de la sociedad ychsma. La organización de estos curacazgos estaba basada generalmente en una ciudad élite, desde la cual se dominaba y regía un determinado espacio geográfico circundante y a la población que en él habitaba.

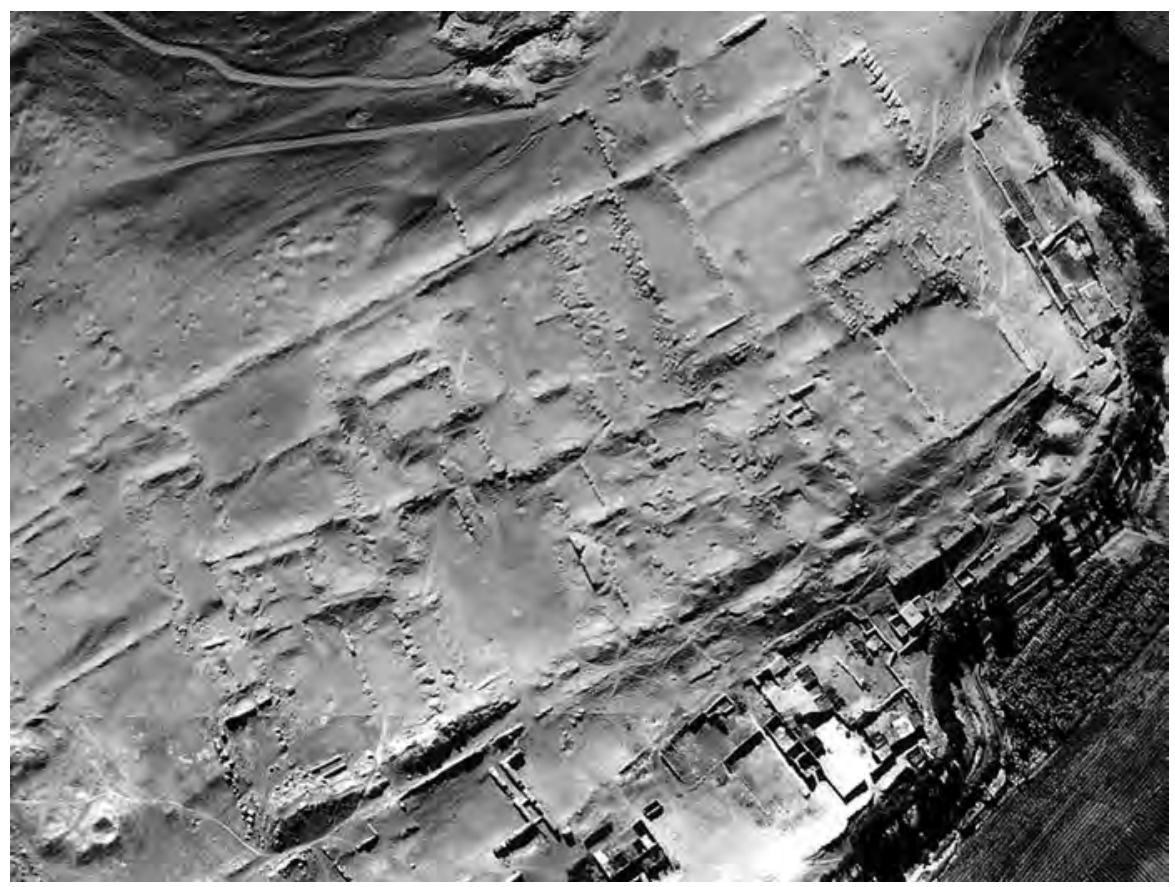

Figura 9. El conjunto arquitectónico denominado Huaca Marcavilca en Armatambo (Detalle de la foto aérea SAN 1943). Obsérvese el amurallamiento de sus contornos y la presencia de Pirámides con Rampa en su interior. 
¿Cuál pudo ser la causa de este cambio tan radical? Es difícil saberlo por la escasez de asociaciones específicas con este periodo, pero algunos indicios parecieran indicar una aislamiento de la región ychsma con respecto a las aledañas, quizás producto de cambios sociales al interior de la propia estructura política ychsma al desagregarse en pequeños curacazgos, presiones étnicas de grupos del entorno, o lo que parece también probable, una suerte de desertificación del medio, motivado por una escasez de lluvias en la sierra en un periodo relativamente prolongado, seguido de un periodo de grandes precipitaciones. Cualquiera de estos factores o la combinación de algunos de ellos, pueden haber motivado los cambios radicales observados en la cerámica, los cuales se reproducen de alguna manera en el patrón de ocupación de los valles bajos, mucho más disperso e intensivo que los periodos precedentes; pues aunque existan pocos reportes para esta fase, varios de los sitios ychsma parecieran originarse o crecer en este periodo, como el de Macattampu o Armatambo por ejemplo (Vallejo, 2005).

La época Ychsma Tardío se diferencia notoriamente de las anteriores por su gran dinamismo. Es especialmente el periodo de gran complejización que experimentan las sociedades del Intermedio Tardío a nivel general. Los cambios visibles a nivel cerámico, son correspondientes con cambios importantes en otros órdenes de la actividad económica, social y cultural de la sociedad ychsma. La iconografía ciertamente se vuelve más compleja y variada que en el periodo Medio. Pero es quizás en la arquitectura y en el patrón urbano donde se notan las modificaciones más importantes. Se pudiera hablar incluso en cambios estructurales en la sociedad ychsma pues las resultantes arquitectónicas, iconográficas y de complejización de muchos contextos funerarios o rituales así lo parecieran demostrar.

Por ejemplo, el modelo arquitectónico de las Pirámides con Rampa en Pachacamac, en- cuentra su mayor difusión en la fase Ychsma Tardío A, coincidiendo quizás con un mayor dinamismo que la sociedad ychsma presenta en aquel periodo (Vallejo, 2005).

Si analizamos el material cerámico presente en cada una de ellas asociado con su uso (Franco 1998, 2004; Eekhout 1995, 1999; Espejo, 2006; Feltham \& Eekhout, 2004) resulta evidente que la mayoría de las PCR corresponden cronológicamente con las fases más tardías de la secuencia ychsma.

\section{Los Talleres Cerámicos}

Sin duda los elementos de variabilidad en la cerámica reflejan un comportamiento social que puede ser de alguna manera explicado y que necesariamente pasa por entender el proceso productivo mismo de la cerámica, especialmente en lo concerniente a los llamados talleres cerámicos. Estos talleres, es decir, los puntos específicos de producción de la cerámica, pueden ser agrupados de dos maneras: El primer tipo cuando se trata de talleres muy especializados con posibilidades de elementos técnico-productivos diversos, pero de rasgos morfológicos y decorativos comunes; y el segundo tipo, cuando se trata de talleres no especializados, con elementos técnico-productivos muy limitados, pero con muchas variantes morfológicas y decorativas.

En cierta manera resulta una paradoja de que a mayor especialización del taller cerámico, cuando las posibilidades productivas de la cerámica son mucho más amplias intercalándose diversas técnicas de modelado o moldeado, con el uso técnicas de cocción diferentes y con un acceso a mayores y mejores materiales utilizados en la decoración como los diferentes tipos de pigmentos, la morfología de las piezas cerámicas, sin embargo, obedece por lo general a un patrón muy estricto, con elementos decorativos igualmente comunes e incluso con diseños complejos pero repetitivos. Las variantes apreciables en este tipo de talleres se dan preferentemente 
por motivaciones artísticas siendo el resultado morfológico y decorativo de piezas muchas veces de características atípicas.

Por otro lado, esta paradoja también se da en el segundo tipo de talleres cerámicos no especializados, pues si bien las posibilidades productivas y técnicas son mayormente limitadas e incluso con poco acceso a materiales tanto de composición de la pasta como de decoración; en lo que a morfología y patrones de diseño respecta, estos talleres reflejan sin embargo muchas variantes, no tanto por la capacidad artística de estos mismos talleres, sino por lo aleatorio del proceso de manufactura y decoración.

Efectivamente, en el segundo tipo de talleres cerámicos, el proceso productivo de la cerámica involucra a un gran conjunto de talleres que funcionan en paralelo. Más que mostrarse un patrón centralizado de los talleres cerámicos o restringido a pocos talleres especializados como se da en el caso del primer tipo, en el segundo tipo el patrón es bastante disperso llegándose incluso hasta unidades familiares independientes. Dicho de otra manera, los talleres cerámicos no especializados, funcionan al interior de muchos asentamientos, utilizando los materiales disponibles en la proximidad de los mismos, solucionando los problemas productivos de la cerámica de manera particular; y aunque pertenezcan estilísticamente hablando a un grupo mayor, en lo estrictamente local o propio de cada taller y artesano, se aplica elementos morfológicos y decorativos que evidencian gran variabilidad cuando se compara la producción de los distintos talleres existentes ${ }^{4}$.

Este segundo tipo de talleres cerámicos, fue por lo común, los que mayormente funcionaron durante el Intermedio Tardío en la costa central, siendo especialmente notorios en los valles bajos del Chillón, Rímac y Lurín. Quizás por ello, muchos arqueólogos tienden en sus trabajos de investigación a clasificar los grupos cerámicos en una serie "estilos" o "subestilos", que hacen mucho más confuso y de difícil interpretación el cuadro social y étnico de esta región durante este periodo.

Un ejemplo claro de investigación aplicada a los talleres especializados del primer tipo, son los talleres chimú del Intermedio Tardío, donde las posibilidades de clasificación para los arqueólogos son mucho mayores, pues en realidad son pocas y casi siempre las mismas formas cerámicas que funcionan como parte integrante de este estilo. Mucho de esta gran homogeneidad morfológica obedece precisamente al carácter especializado de estos talleres cerámicos que utilizan moldes en la manufactura de las vasijas, así como un proceso de producción seriada que en cierta manera estandariza la morfología y la decoración aplicada.

Otro caso resaltante de talleres cerámicos especializados es con respecto a la cerámica inca de estilo cuzqueño, pues esta apenas llega tener alrededor de catorce formas básicas que conforman todo su corpus cerámico (Meyers, 1975) y en donde incluso la decoración aplicada, aun siendo de gran complejidad y refinamiento, es casi siempre similar con muy pocas variantes conceptuales y de diseño.

Por el contrario, en el caso del estilo Ychsma, la morfología de las vasijas y la decoración aplicada es tan variable que resulta muy difícil establecer un corpus completo de la cerámica ychsma. El carácter mismo, de unidad estilística de este grupo social o étnico, resulta difícil de mostrar o evidenciarse claramente en un área determinada; es más, incluso las variantes son

4 Los trabajos etnográficos sobre la producción cerámica efectuados en regiones como Ancash (Druc, 2005) y el Mantaro (Hagstrum, 1989) apuntan a identificar talleres que involucran en algunos casos a gran parte de la comunidad pero que en la práctica se desarrollan como una forma de producción basada en las unidades familiares. Estas comunidades y por ende estos talleres invariablemente se ubican en las cercanías de los lugares de obtención de la materia prima 


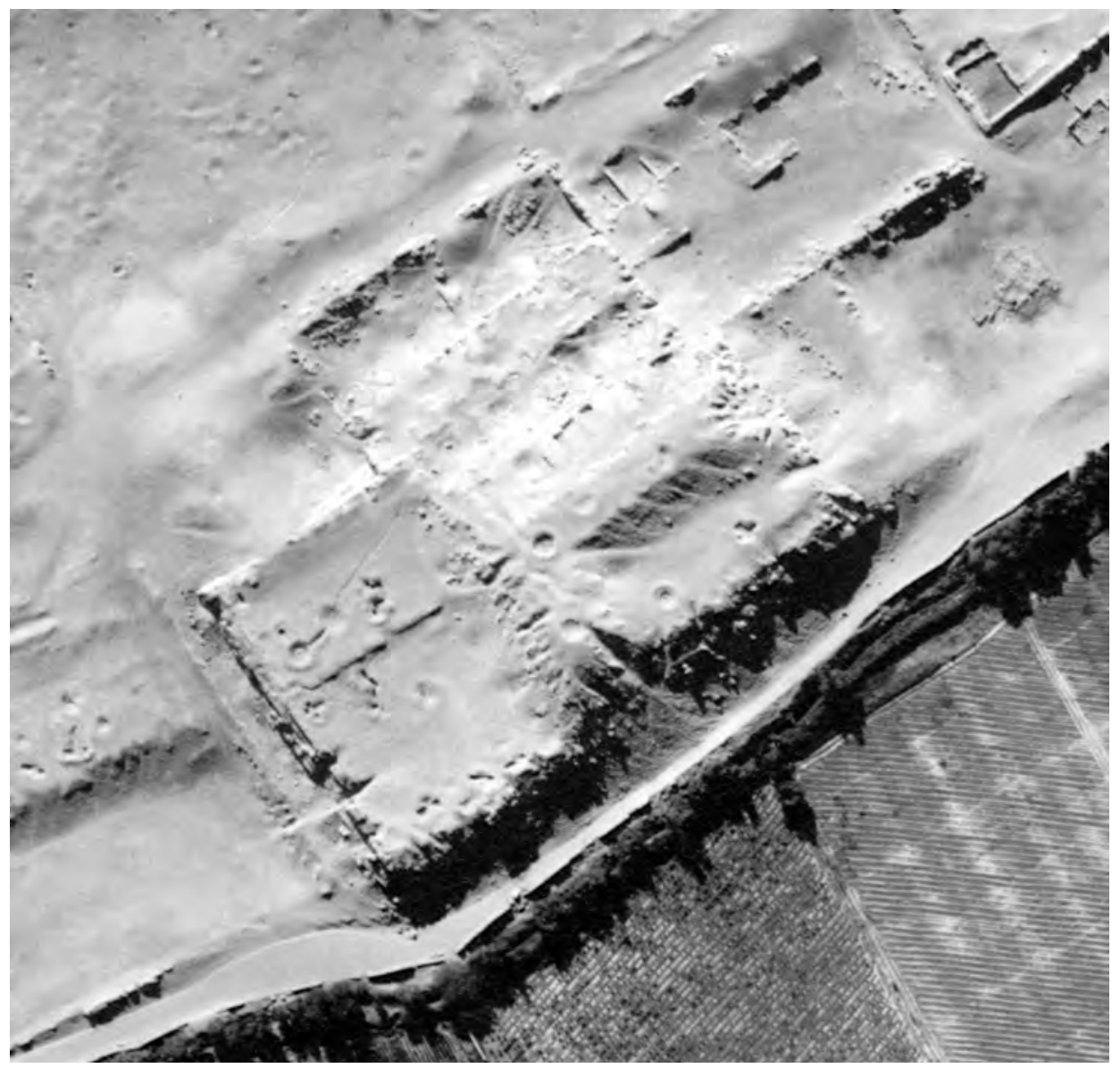

Figura 10. El montículo conocido como Huaca Cruz de Armatambo (Armatambo, detalle foto aérea SAN 1943). Este montículo pertenece a la época ychsma medio y probablemente su función se relacionó con actividades religiosas. La técnica constructiva es típica de esta época, es decir, grandes bloques de tapia con rellenos internos que se suceden en varias fases del edificio.

aun mayores cuando se trata de comparar la producción cerámica entre distintas áreas geográficas más distantes, como el caso de un valle con otro.

Varias explicaciones pueden darse a este cuadro de fragmentación y de localismos estilísticos en el corpus cerámico ychsma, especialmente si aplicamos el criterio de estructura social. Como hemos visto, en los ejemplos de talleres especializados, tanto los chimú como los incas tuvieron unidades sociales fuertes con estados cohesionados y jerárquicamente muy centralizados. Sin embargo, es difícil de precisar si existe una estrecha relación entre la capacidad de cohesión y control de un estado con respecto a la homogeneidad del corpus cerámico que se utiliza en dicha sociedad, aunque la tendencia entre muchos investigadores es que ambos conceptos son directamente correspondientes.

Siempre serían necesarias mayores investigaciones al respecto que involucren en el análisis no solo las variables cerámicas, sino otros elementos que asimismo conforman la base productiva, de organización y de costumbres de determinada sociedad. Por el momento, los más objetivos indicadores de variabilidad en la morfología y decoración cerámica estriban en la 
propia variabilidad de la producción cerámica que se da en los talleres cerámicos no especializados de patrón disperso que coexisten al interior de una sociedad.

¿Cuales son los elementos que dan unidad a un estilo cerámico? o icuales serían los niveles de correspondencia entre capacidad de homogeneidad en la producción cerámica y mayor organización estatal?, son preguntas que pueden enfocarse a través del estudio concreto del funcionamiento y la producción de los talleres cerámicos presentes en esa sociedad.

\section{Conclusiones}

Como hemos tratos de hacer notar a lo largo del presente estudio, el Periodo Intermedio Tardío, resulta muy nebuloso en muchos aspectos fundamentales. Solo por citar el caso de sus orígenes cronológicos es claro que existen muchas opiniones divergentes.

A nuestra manera de ver, la definición del PIT resulta sumamente importante para entender a la sociedad andina en su conjunto. Salvo el periodo incaico, muy referenciado en las fuentes escritas, el PIT es el único periodo preincaico donde aun las fuentes escritas tienen algún grado aproximación o referencia puntual. Su larga duración, la diversidad de entidades étnicas y culturales incluidas y los complejos procesos involucrados hacen del PIT una fuente de investigación imprescindible para entender a las sociedades andinas más tempranas.

El proceso unificador del imperio incaico y la pérdida de autonomía de prácticamente todos los grupos culturales andinos durante el periodo incaico, hacen del PIT el verdadero mapa de la diversidad cultural de la región andina. Diversidad cultural que pareciera existir y renacer antes o luego de cada periodo de "unificación" u horizontalidad cultural andina.

La complejidad social y étnica del PIT representa además la cumbre o el punto más alto en la diversidad cultural andina autónoma previa a la imposición organizativa del imperio incaico. Quizás el hecho mismo que consideremos al imperio incaico como la mayor expresión de la cultura andina nos hace olvidar que la sociedad incaica es producto de la gran complejización que experimentan en general las sociedades andinas en los últimos periodos del PIT. Dicho de otra manera, las bases mismas de la sociedad incaica se fundamentan en la complejidad del PIT.

Siendo el PIT un periodo de por sí bastante extenso cronológicamente hablando, alrededor de medio milenio, es claro que muchos procesos se encuentran involucrados en él. Dentro de estos procesos hemos hecho atención a la variable climática, como elemento de explicación a cambios paralelos y generalizados en casi todas las sociedades andinas correspondientes con el PIT. Desde los procesos de regionalización cultural o estructuración independiente de las sociedades tardías a comienzos del PIT, sucedidos casi todos ellos en el mismo periodo cronológico, hasta los periodos finales de fuerte complejización social que experimentan también todas las sociedades tardías, la variable climática parece haber tenido una notoria influencia en la "horizontalidad" cronológica de estos procesos mayormente coetáneos. Incluso, el propio proceso de expansión incaica, o mejor dicho, la incorporación del elemento de dominio étnico y el copamiento militar de otros espacios físicos por la sociedad incaica del PIT durante el siglo XV, pueden ser el resultado de una estrategia de compensación económica o la búsqueda de nuevas alternativas económicas ante un empobrecimiento o deterioro del medio y especialmente del espacio incaico primigenio debido a cambios climáticos adversos para la reproducción de un sistema adecuado a anteriores condiciones productivas.

La sociedad ychsma no fue ajena a los procesos generales del PIT para el área andina, de hecho fue parte de ellos y muchos de los elementos particulares que encontramos en el desarrollo 
de la sociedad ychsma encuentran su correlato en los procesos de orden generalizado que afectaron también a otras sociedades del PIT. Los trabajos y estudios realizados para definir objetivamente a la sociedad ychsma, son también importantes aportes a la comprensión del PIT y a la diversidad del proceso cultural andino.

\section{REFERENCIAS CITADAS}

Agurto, Santiago

1984 Lima Prehispánica. Municipalidad de Lima Metropolitana. Lima.

Angulo, Lenkiza

2005 Análisis Ambiental del Perú. Consultoría referida a desastres naturales. Consejo Nacional del Ambiente. Lima. Ms.

Bauer, Eva, Martin Claussen, Victor, Brovkin \& Anja Huenerbein

2003 Assessing climate forcings of the Earth system for the past millennium. Geophysical Research Letters 30 (6). American Geophysical Union.

Binford, M, A. Kolata, M. Brenner, J. Janusek, M. Seddon, M. Abbott \& J. Curtis

1997 Climate variation and the rise and fall of the Andean civilization. Quaternary Research 47: 235-248.

Bonavia, Duccio

1991 Perú, hombre e historia. De los orígenes al siglo XV. Edubanco, Lima.

Iriarte, Francisco

2004 La Arqueología en el Perú. Universidad Inca Garcilaso de la Vega. Lima.

Bushnell, G. H.

1962 Perú. Editorial Argos, 212 pp. Barcelona.

Cerdán y Pontero, Ambrosio

1901 [1793] Tratado General sobre las Aguas que Fertilizan los Valles de Lima. En: Leyes, Decretos, Resoluciones, reglamentos y Circulares vigentes en el Ramo de Justicia. Tomo I. Legislación de Aguas, pp.327-515, Edición Oficial, Lima.

Cobo, Fray Bernabé

1882 [1639] Historia de la Fundación de Lima. Imprenta Liberal. Lima.

Cornejo, Miguel

2000 La nación Ischma y la provincia inka de Pachacamac. Arqueológicas 24: 148-173. Museo Nacional de Arqueología e Historia del Perú. Lima.

Dollfus, O. \& D. Lavalle

1973 Ecología y ocupación del espacio en los Andes Tropicales durante los últimos veinte milenios. Bulletin del'Institut Francais d'Etudes Andines 2 (3):75-92, Lima.

Druc, Isabelle

2005 Producción cerámica y etnoarqueología en Conchucos Ancash-Perú. Instituto cultural RUNA, 110 pp. Lima.

\section{Eeckhout, Peter}

1995 Pirámide con Rampa № 3 de Pachacamac, costa central del Perú. Resultados preliminares de la primera temporada de excavaciones (zonas 1 y 2 ). Bulletin del'Institut Francais d'Etudes Andines 24 (1): 65-106, Lima.

1999a Pirámide con Rampa № III, Pachacamac. Nuevos datos, nuevas perspectivas. Bulletin del'Institut Francais d'Etudes Andines 28 (2):169-214, Lima.

1999b Las Pirámides con rampa de Pachacamac. Urpiwachac 1: 14-28. Museo de Sitio de Pachacamac, Lima.

2003 Diseño arquitectónico, patrones de ocupación y formas de poder en $\mathrm{Pa}$ chacamac. Costa central del Perú. Revista Española de Antropología Americana 33: 17-37. Madrid.

2004 Relatos míticos y prácticas rituales en Pachacamac. Bulletin del'Institut Francais d'Etudes Andines 30 (3) : 55-80, Lima. 
Espejo, Juan Carlos

2006 La pirámide N.5 de Pachacamac y la sociedad Ychsma. ConTextos 1: 65108. Lima.

Franco, Regulo

1993 Los dos Templos principales de Pachacamac. Revista del Museo de Arqueología 4: 55-77, Trujillo.

1996 El Templo del Sol de Pachacamac. Esplendor y Poder. Diseño, Prensa e Impresión, Lima.

1998 La Pirámide con Rampa № 2 de Pachacamac. Excavaciones y nuevas interpretaciones. Trujillo.

2004 Poder religioso, crisis y prosperidad en Pachacamac: del Horizonte Medio al Intermedio Tardío. Bulletin del'Institut Francais d'Etudes Andines 33 (3): 465 506, Lima.

Franco, Regulo \& Ponciano Paredes

2000 El Templo Viejo de Pachacamac. Nuevos aportes al estudio del Horizonte Medio. Boletín de Arqueología PUCP 14, Pontificia Universidad Católica del Perú, Lima.

Golfried, Howard

1969 El Salitre, un centro religioso en el valle de Mala. En: Mesa Redonda de Ciencias Prehistóricas y Antropológicas, tomo II: 167-177. PUCP. Lima.

Gonzales, Rosio

2007 Informe Final del Proyecto de Rescate Arqueológico Los Pinos - Huacho. INC. Ms.

Gonzáles-Rouco, Fidel, H. von Storch \& Eduardo Zorita

2003 Deep soil temperatures as proxy for surface air-temperature in a coupled model simulation of the last thousand years. Geophysical Research Letters 30 (21). American Geophysical Union.

Grove, Jean M.

1988 The Little Ice Age. Routlegde. London.
Guerrero, Daniel

2004 Cronología cerámica y patrones funerarios del valle del Rímac: una aproximación a los periodos tardíos. En: Puruchuco y la sociedad de Lima: Un homenaje a Arturo Jiménez Borja, (L. F. Villacorta ed.) pp. 157-177, Lima.

Hagstrum, Melissa

1989 Comunidades alfareras especializadas del valle del Mantaro. Boletín de Lima 61: 29-34. Lima.

Horkheimer, Hans

1970 Chancay prehispánico: diversidad y belleza. En: 100 años de la arqueología Isbell, W. en el Perú. I.E.P. y Petroperú. Lima.

1986 Emergence of city And state at Huari, Ayacucho Peru, during the Middle Horizon. En: Andean Archaeology: 189-200. University of California. Los Angeles.

Jhonson, George

1930 Peru From the Air. American Geographical Society, Special Publication $\mathrm{N}^{\circ}$ 12, 159 pp. New York.

Kroeber, Alfred

1969 El estilo y la evolución de la cultura. Editorial Guadarrama. Madrid.

Kroeber, Alfred \& Clyde Kluckhohn

1952 Culture: A Critical Review of Concepts and Definitions. Papers Peabody Museum of American Archeology and Ethnology 47 (1). Harvard University.

Lhomme, Jean Paul \& Jean Vacher

2003 La mitigación de la heladas en el Altiplano andino. Bulletin del'Institut Francais d'Etudes Andines 32 (2):377399, Lima.

Lumbreras, Luis

1969a De los pueblos, de las culturas y las artes del Antiguo Perú. Moncloa Campodónico editores. Lima.

1969b Acerca del desarrollo cultural en los 
Andes. En: Mesa Redonda de Ciencias Prehistóricas y Antropológicas, tomo II: 125-154. PUCP. Lima.

1974 Las Fundaciones de Huamanga. Editorial Nueva Educación. Lima.

1980 El Imperio Huari. En: Historia del Perú Tomo II: 9-91. Editorial Juan Mejía Baca. Lima.

1981 Arqueología de la América Andina. Editorial Milla Batres. Lima.

2005 Arqueología y Sociedad. IEP. Lima.

Makowski, Krzysztof \& Milena Vega-Centeno

2004 Estilos regionales en la costa central en el Horizonte Tardío, una aproximación desde el valle del Lurín. Bulletin de l'Institut Francais d'Etudes Andines 33 (3): 681-714, (P. Eeckhout editor), IFEA, Lima.

Martín Pastor, Eduardo

1942 El Pueblo del Cacique y los orígenes de la ciudad de Lima. Actas y trabajos cientificos del XXVII Congreso Internacional de Americanistas, Vol. 2, Lima.

Matos, Ramiro

1966 La economía durante el periodo de Reinos y Confederaciones en Mantaro. En: Actas y Memorias del XXXV Congreso Internacional de Americanistas 2: 95-99. Sevilla.

Menzel, Dorothy

1968 La Cultura Wari. Las Grandes Civilizaciones del Antiguo Perú. Tomo VI. Lima.

Meyers, Albert

1975 Algunos problemas en la clasificación del estilo incaico. Pumapunku 8: 7-25, Instituto de Cultura, Municipalidad de la Paz. La Paz.

Morales, Daniel

1984 Algunos sitios arqueológicos del Reino de Guanuco. Boletín de Lima 33: 83-95. Lima.
Nanda, Serena

1980 Antropología cultural: Adaptaciones socioculturales. Wadsworth Internacional - Iberoamerica. New York.

Nielsen, Axel

2002 Asentamientos, conflicto y cambio social en el Altiplano de Lípez (Potosí). Revista Española de Antropología Americana 32: 179-205. Madrid.

Ortlieb L, R. Escribano, R. Follegati, O. Zúñiga, I. Kong, L. Rodríguez, J, Valdés, N. Guzmán $\&$ P. Iratchet

2000 Ocean-climatic changes during the last 2,000 years in a hypoxic marine environment of Northern Chile (23S). Revista Chilena de Historia Natural 73: 221-242.

Ortlieb, Luc \& José Marchare

1989 Evolución climática al final de Cuaternario en las regiones costeras del norte peruano: Breve reseña. Bulletin del'Institut Francais d'Etudes Andines 18 (2): 143-160, Lima.

Paredes, Ponciano.

1985 La Huaca Pintada o el Templo de Pachacamac. Boletín de Lima 41: 70-84. Lima.

1988 Pachacamac- Pirámide con Rampa № 2. Boletín de Lima 55: 41-58. Lima.

Paredes, Ponciano \& Regulo Franco

1987 Pachacamac: Las Pirámides con Rampa. Cronología y Función. Gaceta Arqueológica Andina 13: 5-7, Lima.

1989 "Proyecto: Templo Viejo de Pachacamac (Continuación de estudios)". Segundo informe parcial, 2da. Temporada de Excavaciones, INC. Lima Ms.

Paredes, Ponciano \& Jesús Ramos

1994 Excavaciones arqueológicas en el sector Las Palmas, Pachacamac. Bo- 
letín de Lima 16: 91-96. Lima

Parsons, Jeffrey \& Charles Hastings

1988 The Late Intermediate Period. En: Peruvian Prehistory: 190-229. R. Keatinge Editor. Cambridge University Press. Cambridge.

Parsons, Jeffrey, Charles Hastings \& Ramiro Matos

2000 Prehispanic Settlement Patterns in the upper Mantaro and Tarma drainages. Memoirs of the Museum of Anthropology 34 (1-2). University of Michigan.

2004 Reconstruyendo el Estado en la sierra central del Perú. Interacción entre pastores y agricultores durante el Periodo Intermedio Tardío en la región de Tarama- Chinchaycocha. Investigaciones Sociales 12: 55-98. Instituto de Investigación Histórico Sociales, UNMSM. Lima.

Paulsen, A.

1983 Huaca del Loro revisited: The Nasca-Huarpa connection. En: Investigation of the Andean Past: 98-121. Cornell University. Ithaca.

Perales, Manuel

2004 El control Inka de las fronteras étnicas: Reflexiones desde el valle de Ricrán en la Sierra central del Perú. Chungara 36 (2): 515-523. Tarapacá.

2005 Apuntes sobre el periodo Intermedio Tardío y la presencia inca en la cuenca alta del rió Ricrán, sierra central del Perú. Estudios Atacameños 29: 125-142. Universidad Católica del Norte. San Pedro de Atacama.

Prumers, Heiko

2000 El Castillo de Huarmey: una plataforma funeraria del Horizonte Medio. Boletín de Arqueología PUCP 4: 289-312. Lima.
Ramón, Gabriel

2005 Periodificación en arqueología peruana: genealogía y aporía. Bulletin de l'Institut Francais d'Etudes Andines 34 (1): 5-33, IFEA, Lima.

Ramos C. de Cox, Josefina

1969 ¿Estuvo el oráculo del Rímac en Huatca? La Huaca de los Tres Palos. En: Mesa Redonda de Ciencias Prehistóricas y Antropológicas, tomo II pp. 229-236. PUCP. Lima.

Reyes Flores, Alejandro

1983 Contradicciones en el Perú Colonial. (Región Central 1650 - 1810). UNMSM. Lima.

Rostworowski, María

1972 Breve Ensayo sobre el Señorío de Ychma o Ychima. Boletín del Seminario de Arqueología 13. PUCP, Lima.

1978 Los Señoríos Indígenas de Lima y Canta. IEP. Lima

1981 Recursos Naturales Renovables y Pesca, Siglos XVI y XVII. IEP. Lima.

1982 Dos Probanzas de Don Gonzalo, Curaca de Lima. Revista Histórica 33: 105-187, Lima.

1999 El señorío de Pachacamac: El informe de Rodrigo Cantos de Andrade de 1573. IEP / BCR, Lima.

2002 Pachacamac. Obras completas II. IEP, Lima.

Rowe, John

1959 Tiempo, estilo y proceso cultural en la arqueología peruana. Revista Universitaria 115, 79-96, Cuzco.

1962 Stages and periods in archaeological interpretation. Southwestern Journal of Anthropology, 18(1): 40-54.

Santillan, Hernando de

1968 [1563] Relación del origen, descendencia, política y gobierno de los Incas. Biblioteca Peruana, Primera Serie, Tomo III. E.T.A. Lima. 
Shady, Ruth

1984 Los Estados y Señoríos tardíos. En: "Las Culturas Peruanas", D. Bonavia, Boletín de Lima 34: 9-15. Lima.

Silva, Jorge \& Cecilia Jaime

2005 Etnoarqueología del Bajo Rímac y el Callao prehispánico. Investigaciones Sociales 15: 29-42. UNMSM. Lima.

Soon, Willie \& Sallie Baliunas

2003 Proxy climatic and environmental changes of the past 1,000 years. Climate Research 23: 89-110.

Stumer, Louis

1954 Antiguos Centros de Población en el Valle del Rímac. Revista del Museo Nacional 23. Lima

1956 Desarrollo de los estilos Tiahuanacoides costeños. Revista del Museo Nacional 25. Lima.

Tello, Julio C.

1929 Antiguo Perú. Primera Época. Comisión Organizadora del Segundo Congreso Sudamericano de Turismo. Lima.

Thompson, D.

1970 Habitantes del periodo Intermedio Tardío en la sierra central del Perú. El serrano 19:16-20. Cerro de Pasco Corporation, Lima.

Thompson, Lonnie, M.E. Davis \& E. MosleyThompson

1994 Glacial records of global climate: A 1500-year tropical ice core record of climate. Human Ecology, 22(1): 8395.

Vallejo, Francisco

2004 El estilo Ychsma: Características generales, secuencia y distribución geográfica. Bulletin de l'Institut Francais d'Etudes Andines, 33 (3): 595-642. IFEA, Lima.
2006 Alucinógenos y prácticas chamánicas en los ritos asociados al oráculo de $\mathrm{Pa}$ chacamac. ConTextos 1: 9-64. Lima.

2008 La problemática de la cerámica Ychsma: el estado de la situación y algunos elementos de discusión. Revista Chilena de Antropología. Universidad de Chile. (en prensa).

Villagomez, Pedro de

1919 Exhortaciones e instrucción acerca de las idolatrías de los indios del Arzobispado de Lima. En: Colección de libros y documentos referentes a la Historia del Perú, 1ra Serie, tomo XII. Librería e Imprenta Sanmarti, Lima.

Villalba, R.

1994 Tree Ring and the Glacial Evidence from the Medieval Warm Epoch and the Little Ice Age in Southern South America. Climatic Change 26: 183 197.

Willey, Gordon

1943 A supplement to the pottery sequence at Ancon. En: Archeological studies in Perú 1941-1942 and Columbia studies in Archeology and Ethnology 1(2): 199-215. New York.

Wright Kenneth, Alfredo Valencia \& William Lorah

1999 Ancient Machu Picchu drainage engineering. Journal of Irrigation and Drainage Engineering-ASCE 125(6): 360-369. 